\title{
POST-PRODUCTION HEAVY OIL OPERATIONS: A CASE FOR PARTIAL UPGRADING
}

\author{
A Thesis \\ by \\ TAHER MANSOOR LOKHANDWALA
}

\author{
Submitted to the Office of Graduate Studies of \\ Texas A\&M University \\ in partial fulfillment of the requirements for the degree of \\ MASTER OF SCIENCE
}

\begin{abstract}
Approved by:
Chair of Committee, Maria A. Barrufet

Committee Members, Mahmoud El-Halwagi

Shawn D. Taylor

Ding Zhu

Head of Department, $\quad$ A. Dan Hill
\end{abstract}

December 2012

Major Subject: Petroleum Engineering

Copyright 2012 Taher Mansoor Lokhandwala 


\begin{abstract}
The transportation of heavy oil is a pressing problem. Various methods have been devised to mitigate the reluctance to flow of these highly dense and viscous oils. This study is focused on evaluating a case for post-production partial upgrading of heavy oil. Specifically, we analyze the impact of visbreaking, a mild thermal cracking method, on the economic and energy demands of the post-production process.
\end{abstract}

Using conservative modeling techniques and principles we find significant cost and energy savings can potentially result out of visbreaking. Cost savings result as a consequence of reduced diluent usage. Even the most conservative modeling scenario under consideration exhibits significant cost savings in the form of reduced diluent usage; these savings not only offset operational costs but provide short payback periods on capital expenditures. Additionally, the lower gravity blend resulting from visbreaking can also bring about energy and cost savings in pipeline transportation and positively impact the heavy oil value chain from the producer to a refinery or regional upgrading facility.

From this basic analysis of the potential of visbreaking, we can recommend investing resources to study its viability in the field. Using this analysis as a tipping off point and with a detailed look at the chemistry of the oil in question it is possible to make a very 
viable case for visbreaking. In a similar vein, this analysis can serve as a guide in making a case for other partial upgrading methods as well. 


\section{DEDICATION}

To my dearest fellow cast members:

Mansoor, Rashida and Husein Lokhandwala

and

Raul Medina 


\section{ACKNOWLEDGEMENTS}

It gives me utmost pleasure to acknowledge and thank Dr. Maria Barrufet, my advisor, for her constant help, encouragement, patience and good graces. I feel fortunate to have benefitted from her fantastic tutelage.

Dr. Shawn Taylor was an ardent mentor and advisor. He made it part of his job to lend his support and expertise to my work, and I am very thankful he did.

I am grateful to the many people at Schlumberger who funded my work and lent their time and advice to the project.

I am also incredibly appreciative of Drs. Mahmoud El-Halwagi and Ding Zhu for being members of my committee and teachers that I will remember fondly.

Mr. Robert Nall and Ventech Engineers Ltd. Provided me with an extremely helpful report that gave me a solid base to build from.

Finally, my colleagues and friends have eased my time here and made it memorable and, more importantly, fun. Thanks! 


\section{NOMENCLATURE}

$\underline{\text { Acronyms/Contractions }}$

CAPEX Capital Expenditure

NPV Net Present Value

OPEX Operational Expenditure

SAGD Steam Assisted Gravity Drainage

SP Selling Price

$\underline{\text { Constants/Variables }}$

C Weight concentration of reactant, fraction

d Differential

$\mathrm{E}_{\mathrm{a}} \quad$ Reaction activation energy constant, $\mathrm{KJ} / \mathrm{mol}^{-1}$

$\mathrm{I}_{\mathrm{N}} \quad$ Insolubility number, fraction

$\mathrm{k} \quad$ Reaction constant, $\min ^{-1}$

MW Molecular weight, g/mol

R Universal gas constant

$\mathrm{S}_{\mathrm{BN}} \quad$ Solubility blending number, fraction

SG Specific gravity, fraction

$\mathrm{t} \quad$ Time, min

Temperature, ${ }^{\circ} \mathrm{C}$

$\mathrm{V} \quad$ Volume fraction, fraction

x Molar fraction, fraction

$\alpha \quad$ Empirical parameter between 0 and 1 


\begin{tabular}{|c|c|}
\hline$\delta$ & Solubility parameter \\
\hline$\mu$ & Viscosity, $\mathrm{cP}$ \\
\hline$\rho$ & Density, $\mathrm{g} / \mathrm{cm}^{3}$ \\
\hline \multicolumn{2}{|c|}{ Subscripts/Superscripts } \\
\hline 0 & Value of parameter at time 0 \\
\hline dil & The status-quo dilution case \\
\hline $\mathrm{F}$ & Flocculation parameter \\
\hline $\mathrm{H}$ & Heptane parameter \\
\hline o & Oil \\
\hline s & Solvent \\
\hline $\mathrm{T}$ & Toluene parameter \\
\hline $\mathrm{vb}$ & The visbreaking + dilution case \\
\hline \multicolumn{2}{|l|}{$\underline{\text { Units }}$} \\
\hline API & API Gravity \\
\hline BBL & Barrels \\
\hline $\mathrm{BBL} / \mathrm{D}$ & Barrels/Day \\
\hline $\mathrm{cP}$ & Centipoise \\
\hline $\mathrm{cST}$ & Centistokes \\
\hline KJ & Kilojoules \\
\hline
\end{tabular}




\section{TABLE OF CONTENTS}

Page

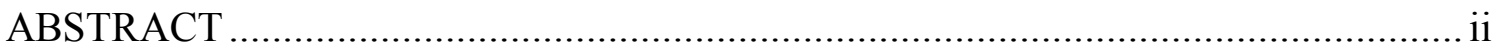

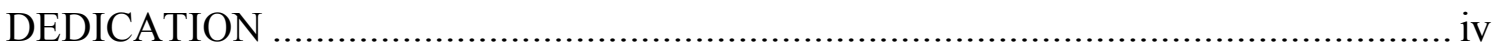

ACKNOWLEDGEMENTS ................................................................................

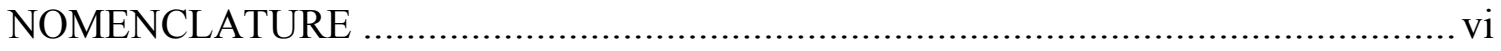

TABLE OF CONTENTS ............................................................................. viii

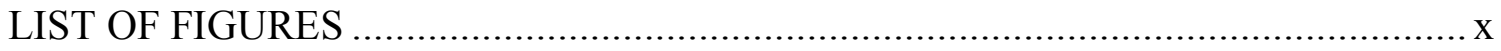

LIST OF TABLES ........................................................................................

1. INTRODUCTION ................................................................................... 1

1.1 Definition of the Problem ....................................................................... 3

1.2 Relevance of the Study .................................................................. 4

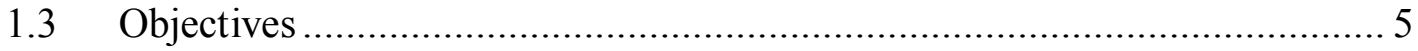

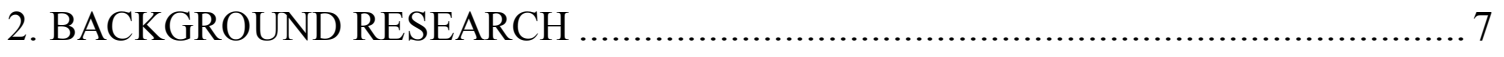

$2.1 \quad$ Value Chain Analysis .............................................................................. 7

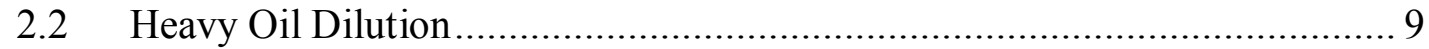

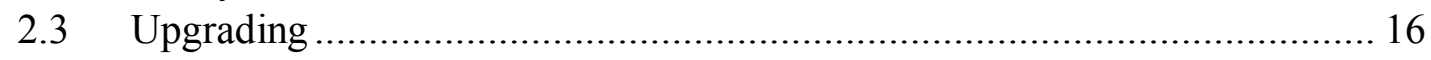

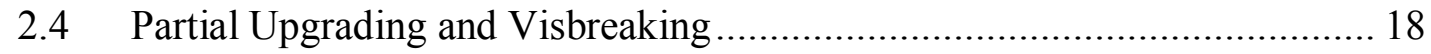

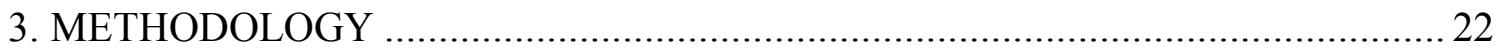

3.1 Input Parameters ............................................................................... 23

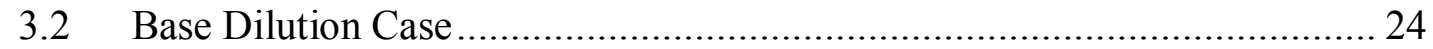

Independent Visbreaker Simulation................................................... 26 


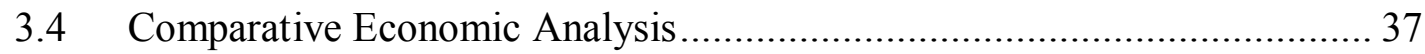

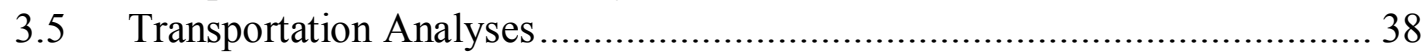

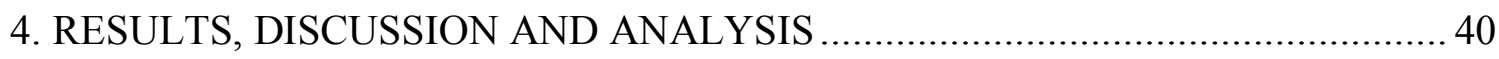

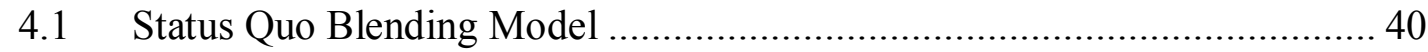

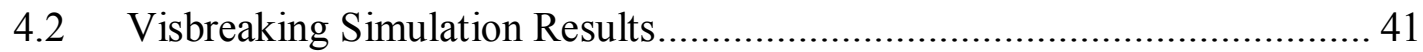

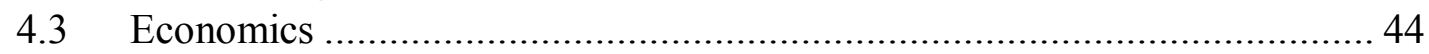

4.4 Cost and Energy Drivers of Differential NPV ………................................ 50

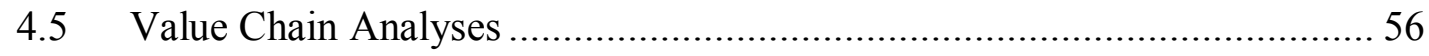

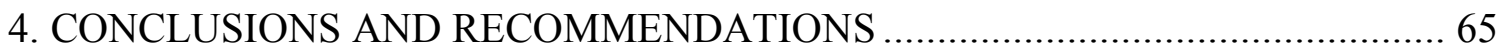

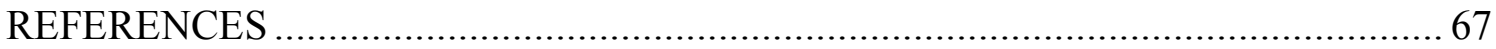

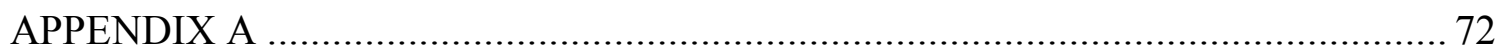




\section{LIST OF FIGURES}

Fig 1 A relevant heavy oil post-production value chain (Wolf \& Tordo 2009)........... 8

Fig 2 Diluent percent by volume in a typical Athabasca bitumen blend (Goshka 2002)....

Fig 3 Semilog Plot of a Cold Lake Bitumen diluted with Naphtha and Syncrude. The blend viscosities are calculated using the Barrufet-Setiadarma blending model (2003)

Fig 4 Cold Lake Bitumen Diluted with Naphtha and Syncrude at transportation viscosities. The blend viscosities are predicted using the Barrufet-Setiadarma model (2003).....

Fig 5 Schematic of an upgrading process. The first stage includes a coking process and the second of hydrogen addition from reforming natural gas.

Fig 6 Schematic of a Typical Visbreaker ..................................................... 20

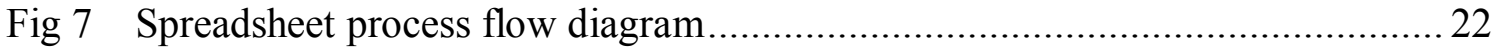

Fig 8 Coke formation curves for residuum and fractions in an open isothermal batch reactor

Fig 9 Details of the pre-visbreaking and post-visbreaking characterizations of the oil into individual components.

Fig 10 Semilog plot of a Cold Lake Bitumen blended with SCO as projected by the Barrufet-Setiadarma model

Fig 11 Cold Lake bitumen product post-visbreaking blended with SCO as projected by the Barrufet-Setiadarma model....

Fig 12 Differential NPV with 8\% and 11\% discounting rate projected over 10 years

Fig 13 Differential NPV as a function of diluent price. The base case is SCO @ $\$ 107 / \mathrm{BBL}$ 50

Fig 14 Change in Differential NPV with Type of Diluent 
Fig 15 Differential NPV as a function of natural gas price. The base case is $\$ 3.05 / \mathrm{MMBTU}$

Fig 16 Differential NPV as a function of visbreaking temperature, with time held constant at 5 minutes........................................................... 54

Fig 17 Differential NPV as a function of visbreaking time, with temperature

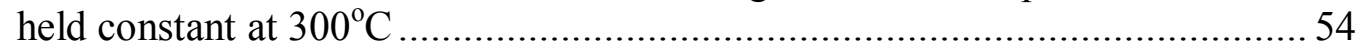

Fig 18 Differential NPV as a function of light ends characterization.......................55

Fig 19 A typical PIPESIM transportation system.............................................. 57

Fig. 20 Pipeline pressure drops for both our scenarios ................................... 58

Fig 21 US Refinery Regions (National Energy Board 2011)............................... 62

Fig 22 Thermal cracking capacity of US refineries .......................................... 63 


\section{LIST OF TABLES}

Table 1 Classification of crude oils according to API gravity, heavy oil is typically

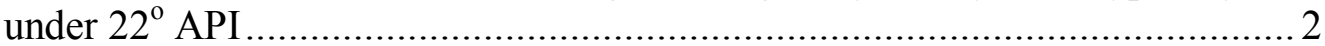

Table 2 Operational and sales expenditures of various production and post-production operations of heavy oil (World Energy Council 2010) ............ 5

Table 3 List of preset oils and solvents. Any combination of these may be used for simulation with minimum user input

Table 4 Coefficients of Equations 5 and 6 for a reactor feed Cold Lake Bitumen....... 30

Table 5 Calculated reaction constants for coke formation from a reactor feed Cold Lake Bitumen at $300^{\circ} \mathrm{C}$

Table 6 Weight fraction of each component converted to coke for a reactor feed Cold Lake Bitumen at $300^{\circ} \mathrm{C}$ for 5 minutes

Table 7 Summary of techniques used to model visbroken product for viscosity ......... 34

Table 8 Composition of visbroken reactor feed CL Bitumen at $300^{\circ} \mathrm{C}$ for 5 minutes.. 35

Table 9 Viscosity correlations based on specific gravity for a CL Bitumen visbroken at $300^{\circ} \mathrm{C}$ for $5 \mathrm{~min}$.

Table 10 Product of visbreaking a Cold Lake Bitumen at $300^{\circ} \mathrm{C}$ for 5 minutes

Table 11 Cost assumption for the economic model

Table 12 Economics for the visbreaking of a $5000 \mathrm{BBL} / \mathrm{D}$ Cold Lake Bitumen production facility

Table 13 Sample differential NPV calculation for a CL Bitumen put through the code.

Table 14 Excess saleable oil transported as a result of vibreaking 59

Table 15 Daily Canadian heavy oil exports to the USA in 2010 (National Energy Board 2011).

Table 16 Database of the density and viscosity of the heavy oils 72

Table 17 Database of the density and viscosity of solvents. 


\section{INTRODUCTION}

Heavy oil accumulations have been documented in more than 30 countries in the world, with the largest reserves located in the Orinoco Belt in Venezuela and Alberta and Saskatchewan in Canada. The International Energy Agency (IEA) estimates that there are 6,000 billion barrels of oil (Bbbl) in place worldwide; with 2,500 Bbbl in Western Canada, 1,500 Bbbl in Venezuela, 1,000 Bbbl in Russia, and 100-180 Bbbl in the United States (Clark et al. 2007).

The petroleum industry commonly classifies crude oil as light, medium, heavy and extra heavy or bitumen. Primarily, classification is based upon its specific gravity or API gravity. Table 1 shows the classification of crude oil according to the Energy Information Administration (EIA). Of particular interest is the range of gravities that classify as heavy. We are used to hearing about the extremely low gravity tar sands and may be lulled into thinking them to be typical of heavy oil gravities worldwide. Table 1 belies that assumption; the EIA considers any hydrocarbons lower than $22^{\circ}$ API as heavy. 


\section{Table 1-CLASSIFICATION OF CRUDE OILS ACCORDING TO API GRAVITY, HEAVY OIL IS TYPICALLY UNDER $22^{\circ}$ API}

\begin{tabular}{|l|c|}
\hline Type of Crude Oil & API gravity \\
\hline light & $>38$ \\
\hline medium & $22-38$ \\
\hline heavy & $22-10$ \\
\hline extra heavy/Bitumen & $<10$ \\
\hline
\end{tabular}

Heavy oil is also characterized by its high viscosity, which presents major obstacles to recovery. Viscosity at reservoir temperature is of primary importance to heavy oil producers. Viscosity often determines both the economics and the technical chance of success for the chosen recovery scheme and is often directly related to the recoverable reserves estimates (Yang 2011). Unfortunately, no clear correlation exists between API gravity and viscosity. Viscosity can vary greatly with temperature, while API gravity can vary little. For instance a light crude with high paraffin content in a shallow, cool reservoir can have a higher viscosity than a heavy, paraffin-free crude in a deep hot reservoir. For similar reasons, oils with equivalent gravities do not necessarily correlate with each other on viscosity.

For these reasons it becomes necessary to use alternate definitions of heavy oil. The World Petroleum Congress defines heavy oil as oil whose gas-free viscosity is between $100 \mathrm{cP}$ and $10,000 \mathrm{cP}$ at reservoir temperature. Further, according to the World Petroleum Congress bitumen has a viscosity greater than $10,000 \mathrm{cp}$, and may even be as high as 1,000,000 cp. As a result, bitumen is predominantly defined as crude oils with a dead-oil or gas-free viscosity $>10,000 \mathrm{cP}$ (Clark et al. 2007). 
Compositionally, heavy oils tend to be higher in sulfur, acidic fractions and other impurities. This coupled with their viscosity means they are impossible to flow in pipelines in their natural state (cold production). The challenges of high viscosity and composition are overcome by one or a combination of a variety of techniques.

\subsection{Definition of the Problem}

Post production transportation of heavy oil through commercial pipelines requires the oil to conform to certain specifications. The specifications in question depend on the lease agreement between the producer and the transportation company. However, the typical lease agreement includes cutoffs on product viscosity, API gravity and sulfur content (Suncor Pipeline Company 2012). Generally, the viscosity, gravity and sulfur content cutoffs for transportation purposes are $350 \mathrm{cSt}, 19^{\circ}$ API and $<2 \%$ by weight respectively (Rahimi et al. 2009). Consequently, the problematic nature of heavy oils discussed earlier necessitates certain post-production operations that make the feedstock conform to transportation guidelines. Most common among these are blending with a diluent or upgrading/partial upgrading on site.

The World Energy Council (2010) report on heavy oils states that in Canada alone about $40 \%$ of the heavy oil produced undergoes blending with diluent for transportation, worldwide this figure is close to $60 \%$. Conversely, post-production upgrading is mainly done on a scale of hundreds of thousands of barrels in Canada where even the smaller facilities are able to handle over thirty thousand barrels a day. This accounts for a 
majority of post-production operations in Canada, around $60 \%$, but leaves a sizable percentage of operations, especially operators of facilities that produce $10,000 \mathrm{BBL} / \mathrm{D}$ or less.

The question we are investigating involves replacing diluent operations with small upgrading units at the wellsite. We analyze the economic ramifications of this decision to the producer as well as along the heavy oil value chain; from wellhead to refinery.

\subsection{Relevance of the Study}

Given there are 6,000 Bbbl of heavy oil in place worldwide, there is an enormous potential, now and in the future, for these resources to be a vital part of the energy landscape. However, given the litany of additional challenges faced in transporting these hydrocarbons to market and converting them into a marketable product the viability of development is often dependent upon the crude oil prices. Table 2 shows some of the additional costs required to make heavy oils into a viable, saleable product. 
Table 2-OPERATIONAL AND SALES EXPENDITURES OF VARIOUS PRODUCTION AND POST-PRODUCTION OPERATIONS OF HEAVY OIL (World Energy Council 2010)

\begin{tabular}{|c|c|c|c|c|}
\hline Production Method & $\begin{array}{c}\text { Quantity } \\
\text { (BBL/D) }\end{array}$ & Product & $\begin{array}{c}\text { OPEX } \\
\text { (\$/BBL) }\end{array}$ & $\begin{array}{c}\text { Supply Cost* } \\
\text { (\$/BBL) }\end{array}$ \\
\hline Cyclic Steam & 30000 & Bitumen & 19 & $34-35$ \\
SAGD & 30000 & Bitumen & 18 & $32-33$ \\
Mining & 100000 & Bitumen & 12 & $34-35$ \\
Integrated mining/upgrading & 100000 & SCO & 22 & 68 \\
\hline
\end{tabular}

*Supply Cost refers to the cost of the fluid at the point of supply to the refinery or processing facility

Given that a large portion of heavy oil producers use diluent in addition to these already existing costs illustrates the importance of cost reduction in the heavy oil value chain. If we were able to find viable alternatives to existing operations, there is a genuine prospect of adding value not only to the producer but other parties involved in the heavy oil value chain. Our attempt to study visbreaking as one such alternative is an attempt at doing exactly that.

\subsection{Objectives}

The objectives of this study are:

1. To investigate the possibility of an economic case for producers to explore using small upgrading units like visbreakers at the wellsite 
2. To explore the impact of using such units along the heavy oil value chain; from the producer, through a pipeline and to the refinery or upgrading facility. 


\section{BACKGROUND RESEARCH}

The use of thermal cracking methods to alter the physical and chemical properties of hydrocarbons is not a novel idea. In fact, there is evidence of laboratory experimentation on thermal cracking of Alberta oils from as early as 1943 (Alberta Research Council 1943). Likewise, there has been extensive research on the topic of blending of heavy oils, which is not altogether unexpected given the widespread use of blending in worldwide heavy oil operations.

\subsection{Value Chain Analysis}

Analysis of the heavy oil value chain is secondary to our main objective of studying the economic feasibility of visbreaking at the source. Nevertheless, there are concepts inherent within the understanding of the value chain that are key to formulating the syntax and the framework within which we will discuss the problem of visbreaking.

The term "value chain analysis" was first coined by Harvard economist Michael Porter (1985). A value chain, Porter says, can only be studied if broken down into its strategically relevant activities. This means that the activities within a value chain must be studied not only with respect to individual industries but within a relevant scale in that particular industry. To drive home this point, a small regional independent heavy oil operator is not going to find the value chain analyses of an integrated producer valuable.

Fig. 1. provides a typical value chain for post-production heavy oil operations, broken down into strategically relevant activities as defined by Porter. 


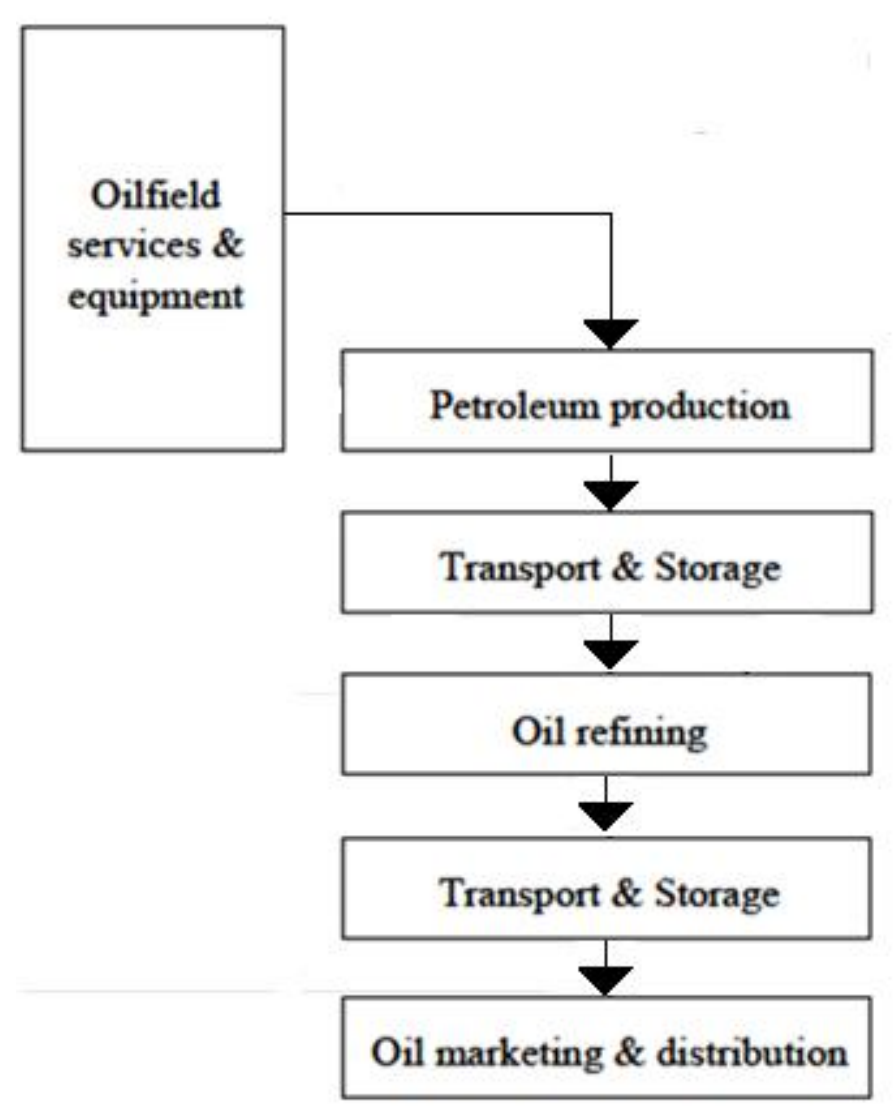

Fig 1-A relevant heavy oil post-production value chain (Wolf \& Tordo 2009)

Arguably, for the producer, we need only consider the "Petroleum Production" and "Transport \& Storage" stages of the chain. However, the refining stage could also impact the heavy oil value chain with regard to the producers and pipelines. For one, refineries are the largest suppliers of naphtha which accounts for a large percentage of diluent usage. Porter claims the assumption that changes in part of the value chain won't affect operations in other parts of the value chain implies that all the strategically relevant activities are mutually exclusive. There is no clear evidence to suggest that this is so for 
heavy oil producers. Therefore, the role of activities downstream in the value chain must be studied to have a full and accurate idea of the impact of changes in any part of the value chain.

Changes within a certain portion of the value chain can be further divided into discreet activities that add value, says Porter (1985). These activities must be designed in order to provide the producer with the maximum possible cost advantage, a consideration that requires the operator to be concerned with the drivers that determine cost. It is this language that we will use to talk about the economics of our project. Framing the problem in terms of cost and energy drivers helps us not only define in detail the activities at the source of our project but also further along the value chain.

\subsection{Heavy Oil Dilution}

As mentioned previously, $60 \%$ of worldwide heavy oil operations are subject to some form of dilution or blending. Blending can occur either in-situ or post-production, and is often done at regular intervals during pipeline transportation to maintain flow assurance within pipelines. Blending remains the popular choice for transportation worldwide. Blending has some natural advantages over other kinds of thermal or energy intensive operations; the setup is relatively simple and has a low capital investment. Additionally, blending avoids the issue of fluid stability that is often a problem with thermal upgrading techniques. Motaghi et al. (2010) confirm that thermal treatment can lead to asphaltene precipitation and form deposits that can subsequently cause corrosion. Furthermore, 
thermal treatment may lead to formation of olefins and diolefins which cause polymerization, making the crude unsuitable for pipeline transport. These problems are mitigated with blending. Often, blending is required even after thermal operations; while not all of the by-products of these operations are transportation range liquids (using viscosity, density and boiling point as variables) they still may have saleable value and may be transported after blending.

\subsubsection{Blending Models}

Classical diluents are usually lighter crudes, condensates or naphtha. Diluent availability, recycling possibilities and, most importantly, dilution efficiency are priorities in diluent selection. Given the wide variety of diluents available and the various cost scenarios under consideration, accurate blending models become essential in order to maximize efficiency. Fig. 2. gives us an idea of various available diluents and their respective efficiencies, which can be defined as the percent by volume of the solvent needed to ensure a suitable transportation viscosity, in a blend with Athabasca bitumen. We can conclude that California Pentane accomplishes the desired objective through the least addition of volume 


\section{DILUENTS IN ATHABASCA BITUMEN BLEND}

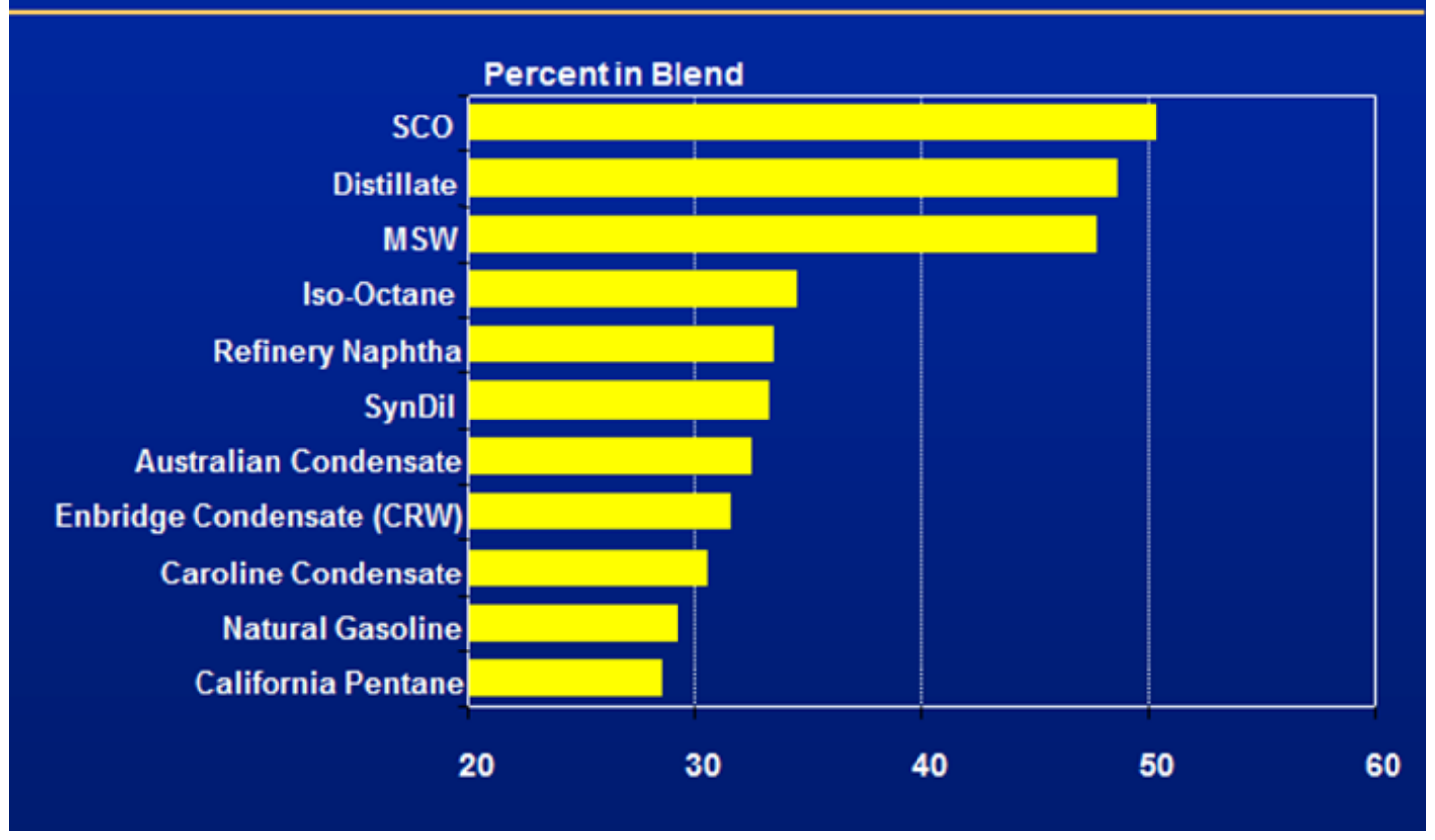

Fig 2-Diluent percent by volume in a typical Athabasca bitumen blend (Goshka 2002)

Of course diluent selection depends primarily on availability and cost of transportation. However, even if these variables are removed from consideration there are several other drivers a producer might be interested in for diluent selection like volume reduction, cost reduction (different diluents have different costs per barrel) and compatibility with the oil. We will touch upon the latter further on, however it is important to note that volume reduction does not necessarily imply cost reduction. Additionally, just achieving cheaper dilution costs at the source may also not be the only objective. For instance, a producer who is an interested party within, say, the transportation portion of a heavy oil value 
chain could rightly want reduced volumes in order to ease the cost of transportation. Given this diversity of scenarios, we can clearly see the need for blending models.

The most well-known mixing rule proposed by Arrhenius uses a weighted average of viscosity and the volume fraction of two fluids to come up with a blend viscosity (Barrufet \& Setiadarma 2003). Shu (1984) proposed the most widely used model for heavy oils based on the classical Arrhenius mixing rule. Heavy oils have physical properties that make them notoriously hard to model with traditional mixing rules. Shu uses an additional weighting factor to modify the existing Arrhenius equation. Shu's rule is presented in Eq. 1.:

$\ln \mu=\left(\frac{\alpha V_{o}}{\alpha V_{o}+V_{s}}\right) \ln \mu_{o}+\left(1-\frac{\alpha V_{o}}{\alpha V_{o}+V_{s}}\right) \ln \mu_{s}$

where $\mu$ is the mixture viscosity in $\mathrm{cP}, \mathrm{V}_{\mathrm{o}}$ is the volume fraction of heavy oil, $\mathrm{V}_{\mathrm{s}}$ is the volume fraction of the diluent, and $\alpha$ is an empirical parameter between 0 and 1 , dependent on the viscosity and gravity of the two fluids.

For the purposes of our study, we use the Barrufet and Setiadarma (2003) model, which is a slight modification on the Shu model, in its definition of the empirical parameter $\alpha$. The Barrufet-Setiadarma model has also been independently evaluated for accuracy (Sutton \& Bergman 2008). The relevant expression is in Eq. 2.:

$\alpha=0.35246295 \times x_{s}^{-0.71154}$ where $\mathrm{x}_{\mathrm{s}}$ is the molar fraction of the solvent. 
Figs. 3 \& 4. shows a comparative study of a dilution study on a Cold Lake bitumen with naphtha and synthetic crude oil (SCO) respectively.

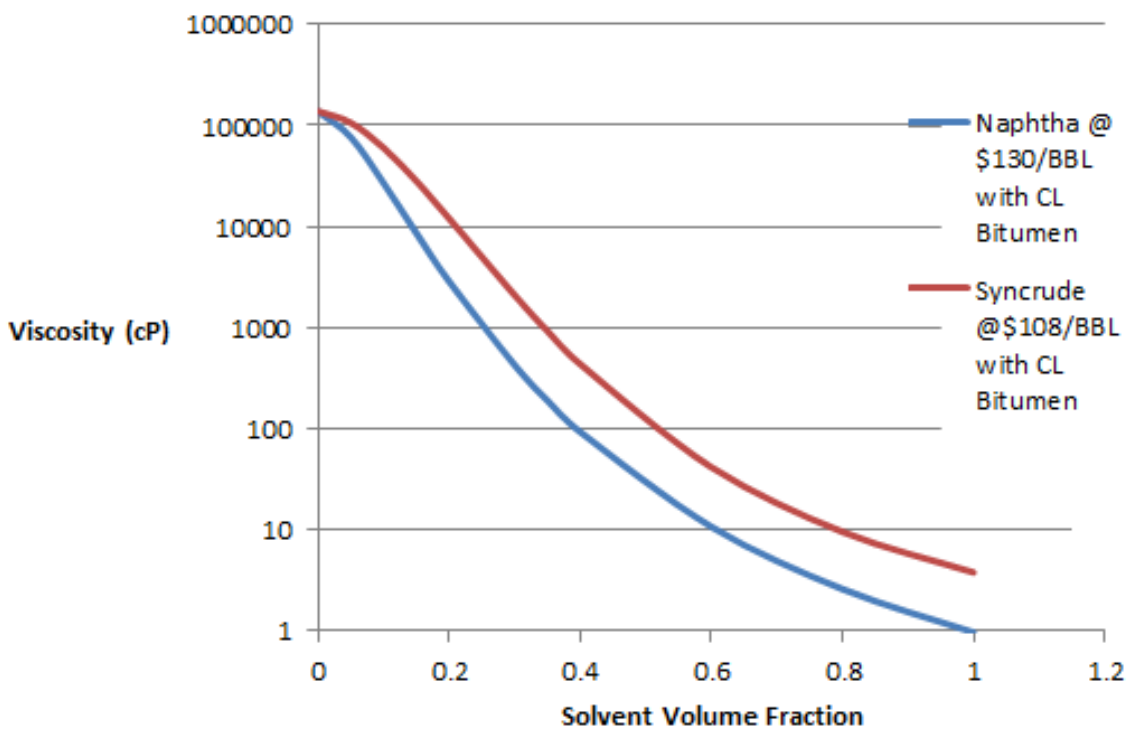

Fig 3-Semilog Plot of a Cold Lake Bitumen diluted with Naphtha and Syncrude.

The blend viscosities are calculated using the Barrufet-Setiadarma blending model (2003) 


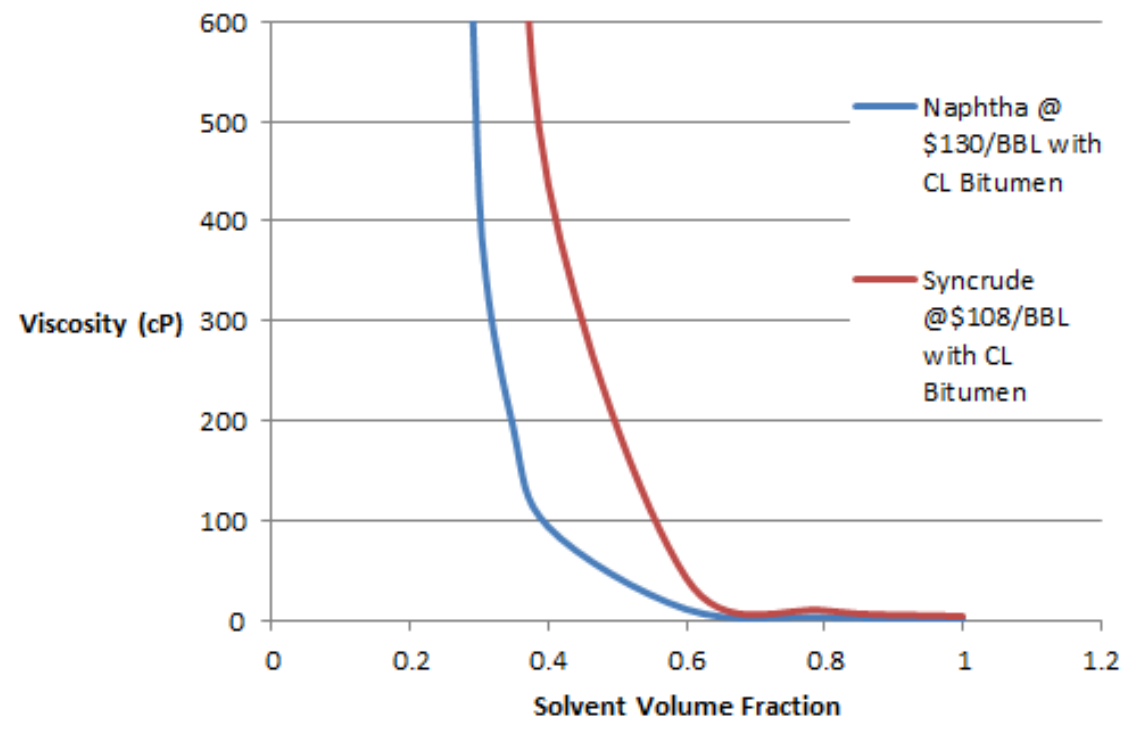

Fig 4-Cold Lake Bitumen Diluted with Naphtha and Syncrude at transportation viscosities. The blend viscosities are predicted using the Barrufet-Setiadarma model (2003)

A closer look at these graphs provides further proof for the necessity of blending models. As the viscosity lowers, the rate of change of the blend viscosity sharply declines. Without an accurate blending model, one might potentially use a large quantity of diluent for not enough of a tangible resulting decrease in blend viscosity. Sutton \& Bergman (2008) point out that various models have ranges of gravities and temperatures where they are more or less applicable. The model we are using is applicable across a wide variety of ranges. Also, the higher the viscosity, the greater is the error in computation. Several blending models exist attempting to create an accurate and universal mathematical computation. However, given that the transportation range 
viscosities that we are evaluating are considerably lower than the original oil viscosity, the error from our blending model is likewise considerably minimized.

\subsubsection{Additional Considerations in Blending}

Another one of the important considerations with regard to blending models is the compatibility both of the oil as well as its asphaltene fraction with the diluent in question. Rahimi et al. (2009) state that this depends on the insolubility number of the crude and solubility blending number diluents, which are dimensionless parameters between 0 and 100 that judge of solubility of oil in toluene. Asphaltenes are known to be soluble in toluene and consequently, the solubility parameters indicate the asphaltene content. Eq. 3 \& Eq. 4 detail the insolubility number $I_{N}$ and the solubility blending number $\mathrm{S}_{\mathrm{BN}}$ :

$$
\begin{gathered}
I_{N} \equiv 100 \frac{\left(\delta_{f}-\delta_{H}\right)}{\left(\delta_{T}-\delta_{H}\right)} \ldots \\
S_{B N} \equiv 100 \frac{\left(\delta_{o i l}-\delta_{H}\right)}{\left(\delta_{T}-\delta_{H}\right)}
\end{gathered}
$$

where $\delta_{f}$ is a flocculation solubility parameter, $\delta_{H}$ is the solubility parameter of nheptane, $\delta_{T}$ is the solubility parameter of toluene and $\delta_{\text {oil }}$ is the solubility parameter of oil. These parameters are obtained experimentally and are defined at atmospheric pressure at a single temperature, T. The values are usually expressed in terms of percentages and the ratio of $\mathrm{S}_{\mathrm{BN}}$ to $\mathrm{I}_{\mathrm{N}}$ is defined as the "P-value" which is an indication of the overall stability of the liquid products. If the proportion of less soluble asphaltene 
increases causing an increase in $\mathrm{I}_{\mathrm{N}}$ or solvent quality lowers causing a decrease in $\mathrm{S}_{\mathrm{BN}}$, the overall stability, i.e. the P-value of the product lowers.

Using these criteria can help rank diluents in terms of stability and compatibility. Crude oils and their diluents must be checked for compatibility, especially with asphaltenes. Not doing so can result in troublesome consequences such as asphaltene precipitation during transportation. This may lead to clogging and corrosion of pipelines. Recent work (Argillier et al. 2005) has shown that solvent polarity may also have important consequences on viscosity reduction. Solvents with higher polarity have been shown to achieve more favorable viscosity reduction.

\subsection{Upgrading}

Upgrading is a term used to refer to operations (in-situ or post-production) that involve thermally altering heavy oil feedstock and converting it into transportation range fluids. Upgrading is particularly important in the Canadian tar sands where massive upgrading operations convert the bitumen and heavy oil into approximately a million barrels a day of SCO. SCO is a transportation range fluid and typically trails Brent Crude selling prices by around $\$ 15 / \mathrm{bbl}$. The lower selling price is due to SCO being a highly aromatic blend of lower distillates that add less value to the refiner (Flint 2004). Conversely, the advantages of SCO are the highly reduced compositions of sulfur and nitrogen making it less problematic than blended heavy oil for refiners. Indeed, SCO is often used as a diluent precisely because of these properties. 
Upgrading today is an extremely involved process. Since upgrading basically targets the reduction of the carbon to hydrogen ratio in order to produce valuable boiling range liquids, the process involves massive amounts of natural gas usage. Flint (2004) estimates that upgraders require upwards of $2000 \mathrm{scf}$ of natural gas/BBL to feedstock. While a reasonable portion, nearly half in fact, of this is used in order to accomplish the in-situ recovery methods discussed earlier, hydrogen addition to the upgraded fuel comprises a majority of the other half of the population. It is important to note here that fuel for upgrading units makes up only about $40 \mathrm{scf}$ of natural gas/BBL. Flint claims that the natural gas usage for hydrogen addition remains one of the primary hindrances to the expansion of upgrading and is not sustainable in the long term. Fig. 5. provides a rough schematic of the upgrading workflow.

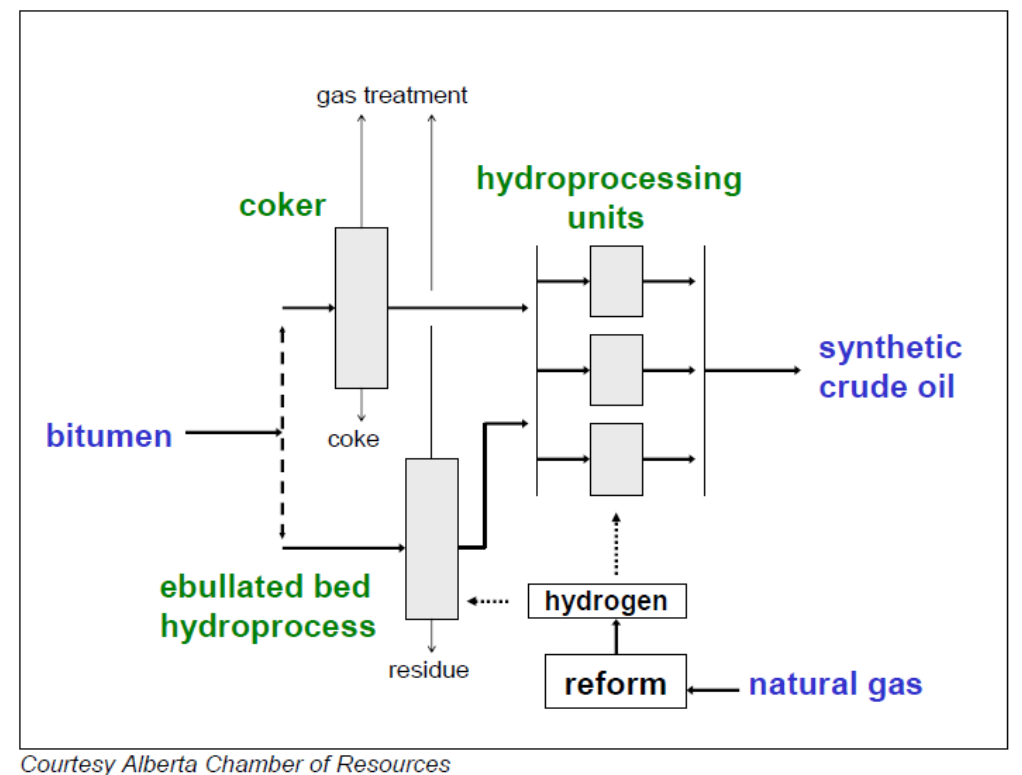

Fig 5-Schematic of an upgrading process. The first stage includes a coking process and the second of hydrogen addition from reforming natural gas. 
Fig.5. also shows the two-stage upgrading process. The first step is most often a coking stage, commonly known as primary upgrading. The coking process converts the feedstock into a residue that is a mixture of gasoline, gas oils, naphtha and tar while releasing gaseous by-products. The resid obtained still has a high quantity of impurities and is a volatile, unstable fluid. The second stage of upgrading solves these problems. This stage consists of hydroprocessing and hydrotreating operations like catalytic cracking in order to produce a blend of liquids that form the transportation range SCO. The secondary upgrading stage does not involve thermal conversion; rather it adds value to the residue produced in the first stage.

\subsection{Partial Upgrading and Visbreaking}

Since upgrading is cost and energy intensive, often only partial upgrading is performed in the field, most of this occurs in-situ during thermal extraction processes. Partial upgrading is precisely what the name implies, a partial thermal conversion process. Some fields already use partial upgrading methods of one form or another. Indeed, there have been studies published detailing the positive impacts of partial upgrading. Motaghi et al (2010) conducted a pilot project with a combination dewatering and deasphalting process they labeled Roseflow. The Roseflow process tested significant economic improvement over status quo blending techniques with cost improvements ranging from $\$ 12-20 /$ bbl. In another process, Fukuyama et al. (2010) tested a cracking process at a steam-assisted gravity drainage (SAGD) production site in Canada. They conclude that not only is the process more profitable than using diluent, but also considerably less 
volatile to market oil and gas prices, a big drawback to the steady production of heavy oil.

Visbreaking, of course, is typically characterized as a partial upgrading process. Wiehe (2011) defines visbreaking as "a low conversion thermal process used originally to reduce the resid viscosity for heavy fuel oil applications. However, more often today it uses a resid that exceeds minimum heavy fuel oil specifications". This definition certainly applies to our study where the feedstock to the visbreaker, far from being within heavy fuel oil specifications, is actually heavy or extra-heavy crude. Eventually, our goal is to have about $20-30 \%$ conversion into transportation range fluids, which is roughly an acceptable estimate of conversion with visbreaking (Wiehe 2011). Visbreaking is essentially a watered down version of coking, with smaller units and shorter reaction times. These operations are much smaller in terms of cost, scale and energy requirements and can be a viable alternative for smaller production operations, particularly in terms of cost savings on diluent. Fig. 6. provides a rough schematic of a traditional visbreaker. 


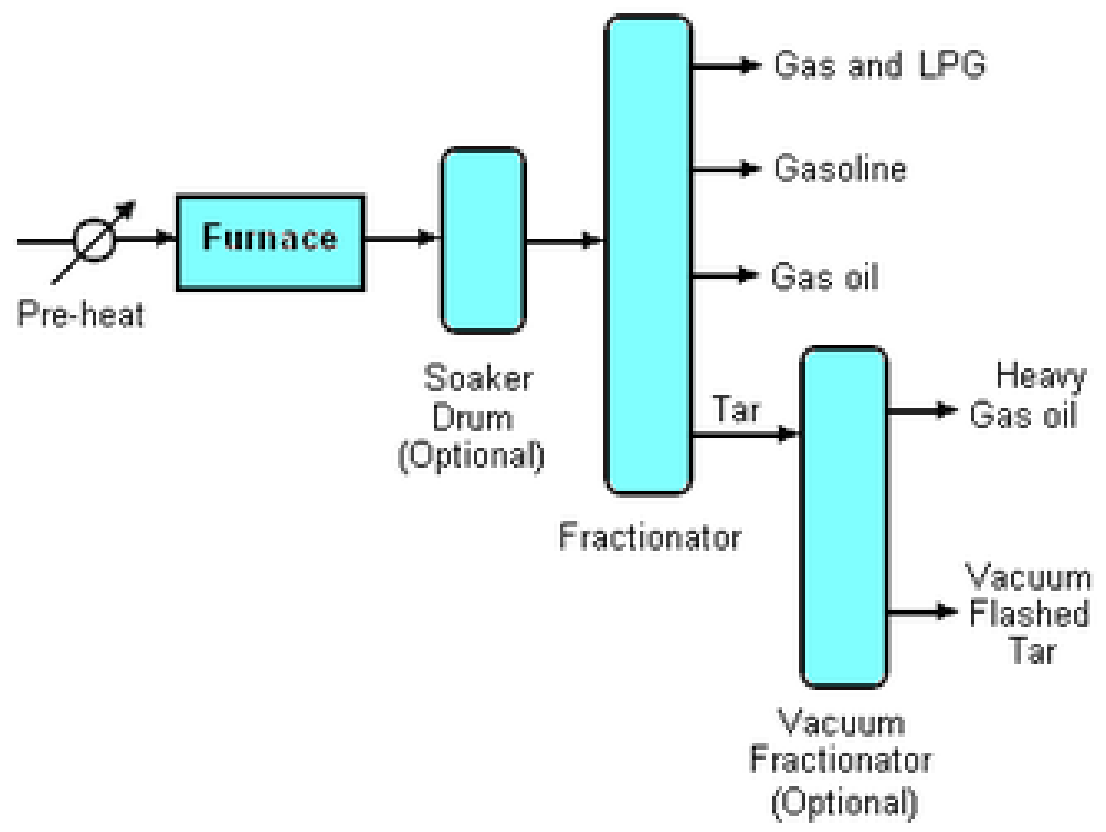

Fig 6-Schematic of a Typical Visbreaker

Visbreakers can broadly be classified as either coil or soaker visbreakers. Coil visbreakers typically operate at higher temperatures of $473{ }^{\circ} \mathrm{C}-500^{\circ} \mathrm{C}$ with short residence times of less than 5 minutes. Soaker visbreakers operate at slightly lower temperatures of $427^{\circ} \mathrm{C}-433^{\circ} \mathrm{C}$ but residence times can be as high as 20 minutes. In coil visbreakers the heat reactions typically take place within a furnace, whereas the soaker visbreaker includes a soaker drum instead, which is heated through the furnace. The reactions take place withing the soaker drum which is much smaller in volume and limits residence times. Fig. 6. in its entirety shows a soaker visbreaker; without the soaker drum it would be a coil visbreaker. Typically coil visbreakers have lower capital costs but higher operational costs, especially with regard to maintenance and coke fouling problems. 
Coke formation remains a major problem within visbreaking. Coke is a heavy solid formed as a by-product of thermal cracking reactions. Coke is extremely undesirable to equipment; it causes fouling of tubes and subsequently, insulation phenomena which severely diminish the heat transfer rates of the equipment. Visbreaking equipment must be routinely cleaned and the coke removed in order to ensure proper operation. Obviously, this adds to maintenance and downtime costs. In addition, coke disposal is also another consequence of coke formation that adds to cost. Although, some research proposed the use of coke as a fuel (Jaykumar 2008) for power generation, this process also involves modification to equipment and is not without investment and environmental concerns. Therefore, it is in our interest to keep coke formation as low as possible.

The question that we then face is effectively a cost-benefit analysis on visbreaking. A report by the Ventech Corporation (2005) provides us a case study that serves as a springboard for this study, while also providing an insight into the potential benefits of visbreaking. A case study conducted by Ventech at a field location in Colombia showed that visbreaking a 10.9 API heavy oil completely eliminated the need for diluent. Indeed, the API gravity increased from over 10.9 to over 20 , the liquid volume increased by $3 \%$ and the acid number was reduced by over $90 \%$. Additionally, Ventech found that the visbreaker operational costs are only around $\$ 1 / \mathrm{bbl}$, a cost far lower than using diluent. They concluded that visbreaking produced transportation range liquids at a far lower cost than blending. 


\section{METHODOLOGY}

With this chapter we will attempt to define the methodology of this research work. A good grasp of the project workflow is vitally important in the understanding of how the goals of this process were achieved through the creation of a software tool. Fig. 7. provides the bullet points of the creation process of the code. This chapter will effectively focus on expanding on each of the salient portions of Fig. 7.

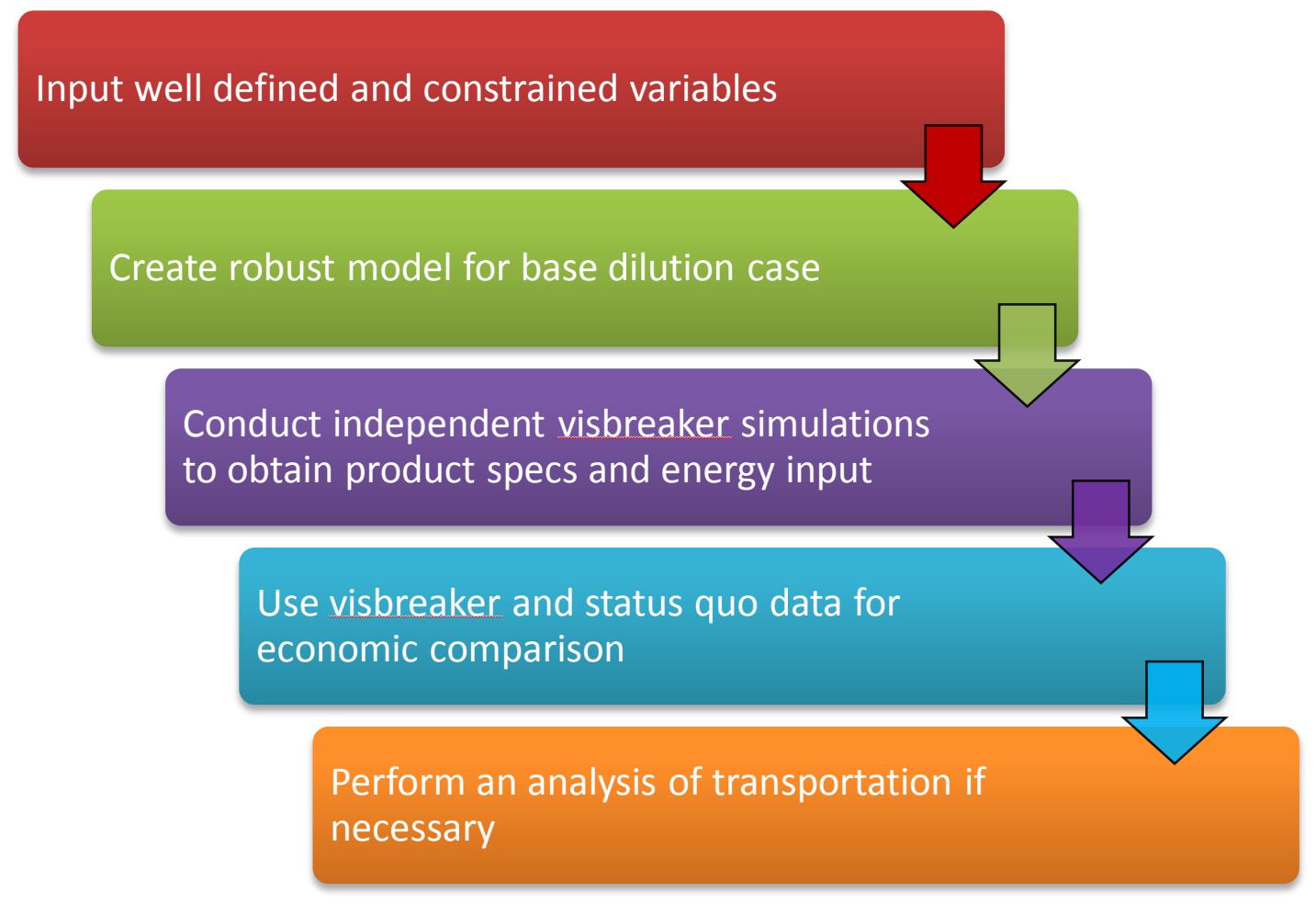

Fig 7-Spreadsheet process flow diagram

This chapter will provide a theoretical basis and some sample calculations whereas the next chapter will provide results and analyses. 


\subsection{Input Parameters}

In order to prepare our model we must first realize the number of variables we need to define. This is not as trivial an exercise as it immediately seems. However, we can answer this by understanding the primary objective of the status quo proposition of blending; which is to make the produced crude oil suitable for transportation. This is accomplished through a reduction in viscosity through blending. Eq. 1. requires viscosity, molar fractions and a volumetric fraction which implies the need for density and molecular weight. Therefore, viscosity, density and molecular weight of the oils and solvents are essential for blending calculations. In order to simulate a visbreaking operation, we need additional inputs like the temperature and the time of reaction. We will discuss this later on. To fulfill all these requirements we have structured two options. The first is a database of oils and solvents that only require inputs of codes denoting the individual fluids, the second allows the user to input their own variables. However, at a minimum this means providing the values mentioned above. In addition, user defined inputs require inputs relevant to the simulation of visbreaking. Presented below is a sample set of input data we will use to provide clarity to some of the equations and theoretical background listed in this chapter.

- $\quad$ Crude Oil (Alberta Research Council 2008): Cold Lake Bitumen @60 $60^{\circ} \mathrm{F}\left(15.55^{\circ} \mathrm{C}\right)$

- $\mu_{\mathrm{o}}=138,000 \mathrm{cP}, \rho_{\mathrm{o}}=1.0023 \mathrm{~g} / \mathrm{cm}^{3}$

- Diluent: SCO @60 $60^{\circ} \mathrm{F}\left(15.55^{\circ} \mathrm{C}\right)$

- $\mu_{\mathrm{s}}=3.8 \mathrm{cP}, \rho_{\mathrm{s}}=0.85 \mathrm{~g} / \mathrm{cm}^{3}$

- $\quad$ Production Volume: $5000 \mathrm{BBL} / \mathrm{D}$ 
- Target Transportation Viscosity: $400 \mathrm{cP}$

- Visbreaking Specifics: $300^{\circ} \mathrm{C}$ for $5 \mathrm{~min}$

Table 3 also lists the oils and solvents that have their properties preset within the code, while Appendix A has details of their fluid properties.

Table 3-LIST OF PRESET OILS AND SOLVENTS. ANY COMBINATION OF THESE MAY BE USED FOR SIMULATION WITH MINIMUM USER INPUT

\begin{tabular}{|l|l|}
\hline \multicolumn{1}{|c|}{ Oils } & \multicolumn{1}{|c|}{ Solvents } \\
\hline Athabasca Bitumen & SCO \\
Cold Lake Bitumen & Naphtha \\
Lloydminster & Toluene \\
& Pentane \\
& Gasoline/Iso-Octane \\
\hline
\end{tabular}

\subsection{Base Dilution Case}

The base dilution case is basically a representation of the Barrufet-Setiadarma (2003) blending model. If we are to properly investigate the impacts of visbreaking, we must have a base case to compare our visbroken product to. This dilution calculation is the base case. The input properties from the first part that define an oil and a solvent are accepted and run in Eq. 1. Assuming a certain blend viscosity at pipeline standards, this 
equation gives us the amount of diluent needed to perform a base dilution operation. Let us set up a sample calculation with a Cold Lake bitumen and SCO. To reiterate, the equations of interest are Eqs. $1 \& 2$ :

$\ln \mu=\left(\frac{\alpha V_{o}}{\alpha V_{o}+V_{s}}\right) \ln \mu_{o}+\left(1-\frac{\alpha V_{o}}{\alpha V_{o}+V_{s}}\right) \ln \mu_{s}$

$\alpha=0.35246295 \times x_{s}^{-0.71154}$

Now, in order to advance our sample calculation we require the molar fraction of the solvent, $\mathrm{x}_{\mathrm{s}}$. This is obtained through knowing the molecular weights of the oil and solvent. Again, our code provides for the molecular weights of the oils and solvents listed in Table 3 (Alberta Research Council 2012). However, the molecular weights may also be calculated using Eq. 5. that provides an estimation of molecular weight based on gravity at standard conditions (Katz \& Firoozabadi 2011).

$M W_{o}=e^{\left(\frac{S G_{o}-0.3098}{0.096}\right)}$

The molecular weights of the Cold Lake Bitumen and SCO for our sample calculation are:

$\mathrm{MW}_{\mathrm{o}}=1215 \mathrm{~g} / \mathrm{mol}$ (Alberta Research Council 2012)

$\mathrm{MW}_{\mathrm{s}}=510 \mathrm{~g} / \mathrm{mol}$ from Eq. 5. 
The molecular weights of SCO reported in different sources vary significantly depending on the chemical composition of the SCO, from approximately $250 \mathrm{~g} / \mathrm{mol}$ to $400 \mathrm{~g} / \mathrm{mol}$ depending on the source (crudemonitor.ca, 2012). Eq. 5. gives us a conservative estimate, but one that fits in with the method of our calculations. Now, using the given data and setting the target viscosity as $400 \mathrm{cP}$, we can calculate that we need $41 \%$ solvent by volume per barrel of oil. Knowing the daily production volume and the cost of solvent per barrel, this translates to:

$\mathrm{V}_{\mathrm{s}}=3420 \mathrm{BBL} / \mathrm{D}$

Cost $=\$ 366,000 / \mathrm{D}$

\subsection{Independent Visbreaker Simulation}

Visbreaking simulation is similar to the simulation of refinery operations, or other thermal cracking operations. Typically, simulation of such operations is very rigorous. Software programs like Aspen HYSYS are used for modeling the processes. For the thermal cracking of heavy oils, programs such as these require copious amounts of heavy oil assay data, including viscosities, densities and boiling points of the chemical fractions making up the feedstock (Aspen 2012). Heavy oil assay data, for this reason is typically quite closely guarded and not easily available in the public sphere.

That said, there is no dearth of attempts at modeling thermal cracking of heavy oil (Henderson \& Weber 1965, Hayashitani et al. 1978, Agroskin et al. 1978, Shu \& Venkatesan 1985, Wiehe 1993). These are all primarily based on experimentation and 
require certain specific data like reaction rate constants, heats of reaction, and thermal capacities. However, there is some knowledge to be gained from all these methods in order to characterize our oils. It would be a worthwhile exercise to touch on one or two of these individually. Hayashitani et al. (1978) developed an extensive model to estimate thermal cracking in Athabasca bitumen. He breaks down the bitumen fractions into coke, asphaltenes, heavy fuel oils, distillates and gas. Eventually, these components are arranged into a matrix of reactions each with its own reaction constants to finally determine the chemical makeup of the product. Shu and Venkatesan (1985) instead perform experimental analyses of visbreaking on different heavy oils to broadly gauge parameters such as asphaltene content, coke formation and viscosity reduction over time. Once again, like the Hayashitani et al. (1978) paper, this is a specific study that is not entirely suitable to the objectives we are trying to achieve.

The holy grail, as it were, of this study is to characterize a visbroken product in terms of our initial oil characterization of density, viscosity and molecular weight. In order to achieve a comparative analysis and investigate the viability of our proposition, this visbreaking characterization is the most vital objective. At this juncture, mentioning the difficulty of standardizing heavy oil characterization would also be a worthwhile exercise. The thermal cracking models we have seen are specific with regard to the oils they are applicable to, or the data they require. What we are trying to achieve is a universally applicable test for heavy oils based on limited inputs. Admittedly, this test would find use only as a preliminary evaluation, however, it is quick to run and 
identifies value and energy drivers that need to be paid attention to in the event of any future detailed analyses.

\subsubsection{Modeling Coke Formation}

As previously mentioned, coke formation in visbreaking is an important cost concern in any economic model that we postulate. Coke is also not typically a saleable product, rather it is a by-product from thermal cracking that provides us with saleable liquids. The coke formation model proposed by Wiehe (2011) is currently the most widely accepted.

Fig. 8. is an example of Wiehe's model of coke formation.

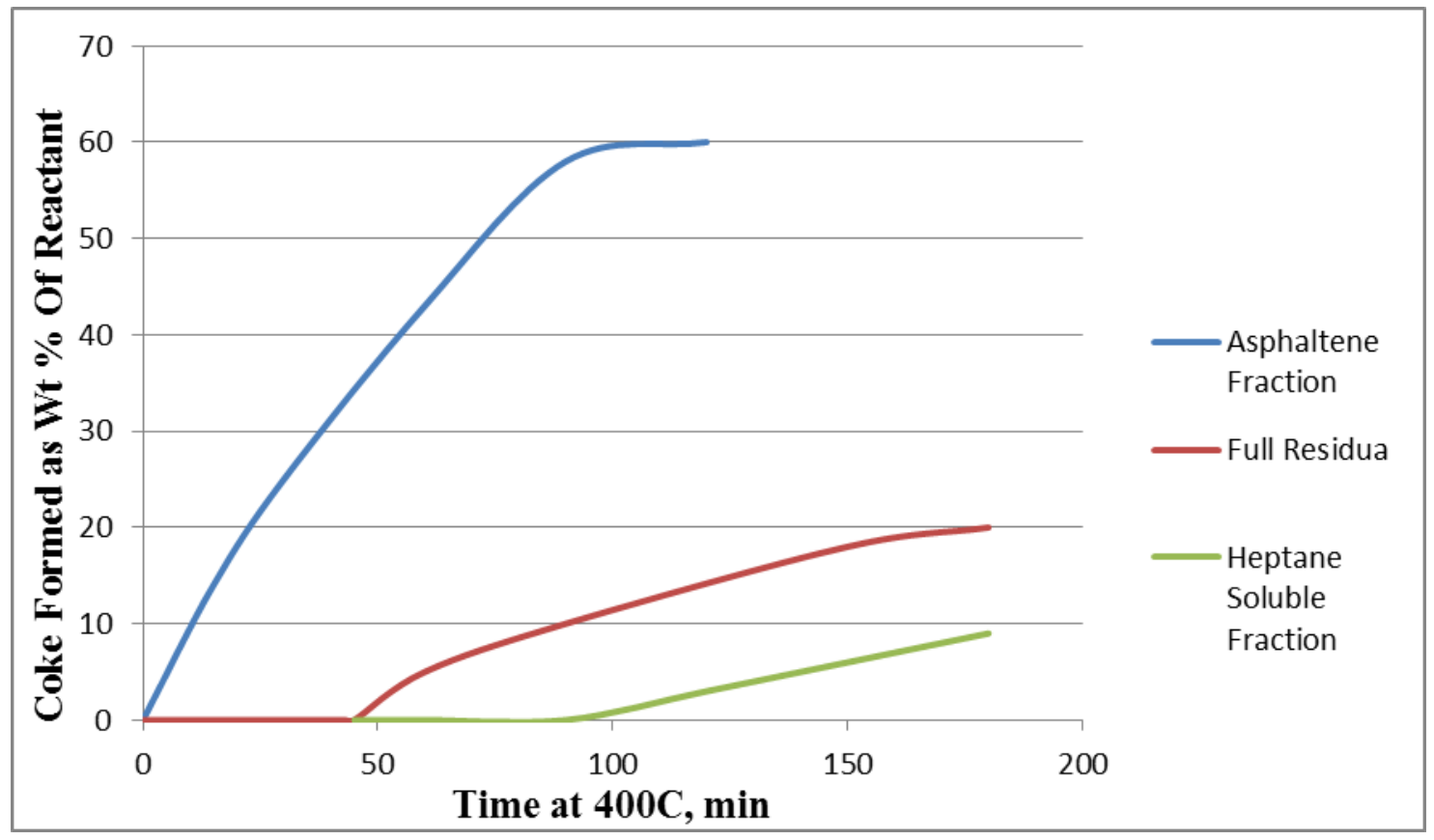

Fig 8-Coke formation curves for residuum and fractions in an open isothermal batch reactor 
Fig. 8. shows a coke formation in a residuum and its fractions subject to heating in an open isothermal reactor. The heptane insoluble asphaltene starts to form coke instantaneously until it reaches a plateau of approximately $60 \%$ by weight of the asphaltene. With the heptane soluble fraction, there is an extensive lag time to be seen prior to the initial coke formation. This lag time is called the coke induction period. For the full residuum this coke induction period is markedly lower. Another important takeaway from this model is the initial first order behavior of coke formation. Coke formation for all three fractions follows first order reaction kinetics until higher order kinetics later on in the reaction life cause the coke formation to plateau out. Eqs. 6 \& 7 are the Arrhenius equations that represent a first order kinetic reaction

$\ln \left(\frac{C}{C_{i}}\right)=k t$

and

$k=k_{0} e^{\frac{-E_{a}}{R T}}$

where $\mathrm{C}$ is the weight fraction concentration of the reactant, $\mathrm{k}$ is the product-specific reaction constant and $\mathrm{E}_{\mathrm{a}}$ is the activation energy

The initial first order nature of coke formation is reported in an earlier study by Banerjee et. al. (1985). Banerjee et al. also make empirical calculations for rate constants and activation energies by cutting the oil into components. Table 4 provides the relevant information for our sample calculation: 
Table 4-COEFFICIENTS OF EQUATIONS 5 AND 6 FOR A REACTOR FEED COLD LAKE BITUMEN

\begin{tabular}{|c|c|c|c|}
\hline Fraction & $\mathbf{k}_{\mathbf{0}} \mathbf{( 1 / \mathbf { m i n } )}$ & $\mathbf{E}_{\mathbf{a}}\left(\mathbf{K J} / \mathbf{m o l}^{\mathbf{1}}\right)$ & $\begin{array}{c}\mathbf{C}_{\mathbf{i} \text { (weight }} \\
\text { fraction })\end{array}$ \\
\hline Asphaltene & 464 & 41 & 0.25 \\
Light Resid & 87.3 & 40 & 0.27 \\
Heavy Resid & 65.1 & 40 & 0.10 \\
Aromatics & 923 & 52 & 0.21 \\
\hline
\end{tabular}

The coke formation is modeled by splitting the oil into four components defined by Banerjee et al. (1985): asphaltenes, light resid, heavy resid and aromatics. Each of these fractions has unique reaction constants and activation energies; these are programmed into the code. Each of the constants presented above are the experimentally obtained constants for the respective fractions to be converted into coke. We also assume no coke induction time. We know from Wiehe (2011) that this is not strictly accurate for fractions that are not asphaltenes but this helps to maximize our coke disposal volumes and other costs, thus keeping our economics conservative. Assuming coke formation to only follow first order kinetics also accomplishes this objective.

Now, using a value of $\mathrm{T}=300^{\circ} \mathrm{C}$ in Eq. 7 and the constants in Table 4, we are able to calculate the rate constants for each fraction: 
Table 5-CALCULATED REACTION CONSTANTS FOR COKE FORMATION FROM A REACTOR FEED COLD LAKE BITUMEN AT $300^{\circ} \mathrm{C}$

\begin{tabular}{|c|c|}
\hline Fraction & $\mathbf{k}\left(\mathbf{m i n}^{\mathbf{- 1}}\right)$ \\
\hline Asphaltene & 0.09 \\
Light Resid & 0.02 \\
Heavy Resid & 0.01 \\
Aromatics & 0.02 \\
\hline
\end{tabular}

Table 5 presents the reaction rate of each component as they form coke at our sample temperature.

Table 6-WEIGHT FRACTION OF EACH COMPONENT CONVERTED TO COKE FOR A REACTOR FEED COLD LAKE BITUMEN AT 300 ${ }^{\circ} \mathrm{C}$ FOR 5 MINUTES

\begin{tabular}{|c|c|c|}
\hline Fraction & Initial Concentration & Final Concentration \\
\hline Asphaltene & 0.25 & 0.16 \\
Light Resid & 0.27 & 0.24 \\
Heavy Resid & 0.1 & 0.09 \\
Aromatics & 0.21 & 0.19 \\
Saturates & 0.17 & 0.17 \\
Coke & 0 & 0.14 \\
\hline
\end{tabular}


Table 6 uses the reaction rates in Eq. 6. for a time of 5 minutes to calculate the amount of each that remains after a portion of each is converted to coke. Clearly, asphaltenes are the most prone to coke formation. This bears out the evidence provided by Fig. 8 . The weight concentration of coke formed is dependent upon the initial concentration of these components in the visbroken feedstock. For the oils stored within the code, these values are included. However, in the event that the user wishes to study the visbreaking of oils not included in the database, they must enter these values manually. Typically, a crude oil assay should provide the user with this information. However, the code is dependent on the user to include accurate assay information. The equations are viable regardless of the information entered, but they do not check for numerical accuracy. However, in the event that information is unavailable or results inaccurate, the user can simply enter a value for "desired coke formation" which is expressed as a fraction. While the latter option undoubtedly compromises accuracy, a targeted conservative value entered for this option still provides a respectable estimate of the efficacy of visbreaking. This is a particular strength of this program, it separates the modeling of coke formation from the modeling of the product stream needed to calculate viscosity. The coke formation is modeled for each component through Eqs. $6 \&$ 7, and summed to calculate total coke formed for a particular visbreaking time and temperature.

\subsubsection{Modeling Fluid Viscosity}

The composition of the final product is structured with the ultimate aim of modeling fluid viscosity. With this in mind, we break our final product into four pseudo- 
components that we shall label, rather uncreatively, as the following: coke, light, heavy and gas.

It is important to note that this characterization differs from our earlier characterization of the oil. Fig. 9. details the process of characterization as the oil goes through the visbreaking process.

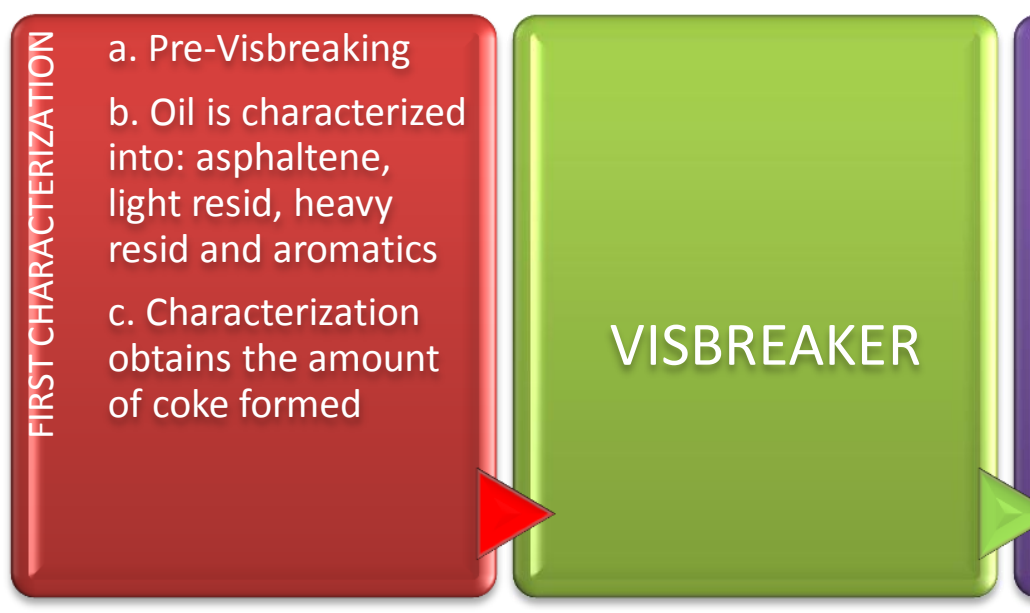

a. Post-Visbreaking

b. Oil is characterized into: gas, light, heavy and coke

c. Characterization calculates visbroken fluid viscosity and density

d. Coke fraction is the result of the first characterization

Fig 9-Details of the pre-visbreaking and post-visbreaking characterizations of the oil into individual components

The components that constitute the second characterization are presented in Table 7. Table 7 elaborates on how the weight percent of each characterization is modeled. 
Table 7-SUMMARY OF TECHNIQUES USED TO MODEL VISBROKEN PRODUCT FOR VISCOSITY

\begin{tabular}{|c|c|}
\hline Component & Characterization (All concentrations in Wt. \%) \\
\hline Coke & Modeled using first order coke formation reactions \\
Gas & Capped at 5\%. Varies between 2-5\% depending on visbreaking \\
& severity \\
Light & Capped at 30\%. Varies between 20-30\% depending on visbreaking \\
Heavy & Severity \\
\end{tabular}

The rationale for each of these characterizations is different. We have already Wiehe (2011) states that visbreaking, used on heavy oils, "converts just enough to obtain 20 to $30 \%$ transportation boiling range liquids and still have the heavy product to meet heavy fuel oil specifications". We characterize the light fraction as these "transportation range liquids" and cap their conversion at $30 \%$. We maintain the range of Wiehe and assign conversion to the light fraction as dependent on visbreaking severity. This is scientifically consistent while also maintaining our objective of conservative modeling. Visbreaking severity is defined by temperature and time. The higher these two drivers are, the more is the light ends conversion. However, on the flip side this also means that coke formation is higher, as evidenced by Eqs. $6 \&$ 7. Finding the right balance between a maximum conversion to saleable product and mitigating coke fouling costs is essential. 
In order to model the remaining components we cap gas formation at $5 \%$ by weight (Bozzano et al. 2005). Although this is a fairly significant weight fraction of gas; it ensures conservative modeling while also ensuring remaining scientifically accurate. After the calculation of coke, and the modeling of the light component and gas, we assign the remaining fraction as heavy through a mass balance. Table 8 presents the composition of each fraction for our case.

\section{Table 8-COMPOSITION OF VISBROKEN REACTOR FEED CL BITUMEN}

AT $300^{\circ} \mathrm{C}$ FOR 5 MINUTES

\begin{tabular}{|c|c|}
\hline Component & Weight Fraction \\
\hline Gas & 0.02 \\
Light & 0.20 \\
Heavy & 0.64 \\
Coke & 0.14 \\
Total (Oil) & 1 \\
\hline
\end{tabular}

Once we have compositional volumes of each fraction, the next step is to embark on the all-important mission of determining the viscosity of the visbroken product. Several viscosity correlations exist that determine viscosity as a function of specific gravity for heavy oils (Egbogah \& Ng 1990, Bennison 1998 \& Miadonye et al. 2001). However, upon testing these models all provided wildly differing results, as shown in Table 9. 
Table 9-VISCOSITY CORRELATIONS BASED ON SPECIFIC GRAVITY FOR A CL BITUMEN VISBROKEN AT $300^{\circ} \mathrm{C}$ FOR 5 MIN.

\begin{tabular}{|c|c|}
\hline Viscosity Correlation & Viscosity Value (cP) \\
\hline Egbogah \& Ng (1990) & 8,421 \\
Bennison (1998) & 21,958 \\
Miadonye et al. (2001) & 31,708 \\
\hline
\end{tabular}

We also have an idea of what the component fractions of our product are like, so we are able to characterize them. This method is also consistent with our mantra of conservative modeling. We wish to characterize these fractions conservatively so as to retard the potential benefits of visbreaking. Since our modeling is not wholly rigorous, applying aggressive factors to such data would be unwise. Instead, with the use of conservative modeling we are able to fulfill the use of this work as a good, standardized screening test for the viability of visbreaking. For the light, transportation boiling range fluids, we use a characterization of $\mathrm{C} 20$ chain compounds, which is a higher characterization. For the heavy fraction, we do use the Bennison (1998) model for viscosity as a function of density.

Armed with the knowledge of the viscosity values of the light and heavy fractions, along with their densities and composition, we use Eq. 1. to calculate liquid product viscosity as a blend of the heavy and light components. With this equation and the knowledge of the properties of each component, we are able to break down the properties of the final 
product into the categories of viscosity, density and molecular weight. This is our new visbroken oil. The details of this calculation are present in the following chapter in Section 4.2. We now use this oil in another dilution operation and come up with results through comparative analyses. The heavier fraction doubles as the "oil" in Eq. 1. while the lighter fraction doubles as the "solvent". The gas is flared and not considered as part of the solvent. However, there may be a case made for blending with gas. Several studies have been conducted into the reduction of viscosity with gas solubility (Quail et. al. 1987, Mehrotra et al. 1989, Jooybari 2012). Given the very high transportation pressures (upto 1400 psi in some cases), a case may be made for using this gaseous portion as a solvent. The gas may also have heating value that would allow the visbreaker to be selfsustaining. This possibility is explored in greater detail in the next chapter.

\subsection{Comparative Economic Analysis}

The visbroken product is put through the blending equation, which gives us the reduced cost and volume of diluent. The overall costs of using a visbreaker are compared to those of using blending. Finally, we take a look at both scenarios while varying different cost and energy drivers to observe their effects on the economics of our study. Based on the cost model, we project these numbers over a ten year period and calculate a "differential NPV”. Eq. 8. describes the differential NPV.

$d(N P V)=N P V_{v b}-N P V_{d i l}$

where $N P V_{v b}$ is the NPV of visbreaking over ten years and $N P V_{d i l}$ is the NPV of the cost of the status quo dilution over ten years. 
Eq. 9. is an expansion of the ten year NPV specified in Eq. 8.

$d(N P V)=\sum_{i=1}^{10} N P V_{i}\left\{\left(S P_{v b}-O P E X_{v b}-C A P E X_{v b}\right)-\left(S P_{d i l}-O P E X_{d i l}\right)\right\}$

The ten year differential NPV, $d(N P V)$, is $\left(N P V_{v b}-N P V_{d i l}\right)$ summed each year for ten years. Specifically, the yearly NPV is simply the cash flow discounted to year 0 , that is the discounted difference between the selling price of the oil and the expenditure of the visbreaking or dilution operation. Now we assume Eq. 10. to be true, that is, that both products are sold at the same rate. While in reality the visbroken oil would be a more valuable product, this assumption feeds into our conservative modeling techniques. $S P_{v b}=S P_{d i l}$

Eq. 8. can then be restated as Eq. 11.

$d(N P V)=\operatorname{Cost} N P V_{d i l}-\operatorname{Cost} N P V_{v b}$

The Cost NPV term is simply the summation of the NPVs of the capital and operation expenditures of each procedure over a ten year period. The results of this analysis will be touched on in the following chapter, in Section 4.3.1.

\subsection{Transportation Analyses}

This section addresses the value chain effects of visbreaking. Through the modeling process we have gathered enough physical data on the fluids to perform a transportation analysis. For this purpose, we use the PIPESIM software (SLB 2012). PIPESIM allows the user to input a black oil fluid model and construct a pipeline transportation network to study the effects that a lowered density and viscosity will have on transportation cost 
and energy drivers. Like the economic analysis, this section will enjoy more thorough coverage in the next chapter. 


\section{RESULTS, DISCUSSION AND ANALYSIS}

This chapter will primarily focus on the visbreaking simulation results, economic and transportation analyses of the sample case study put through the process described in the previous chapter.

\subsection{Status Quo Blending Model}

Using the information in the previous chapter we put the original fluid through the Barrufet-Setiadarma equation which yields Fig. 10.

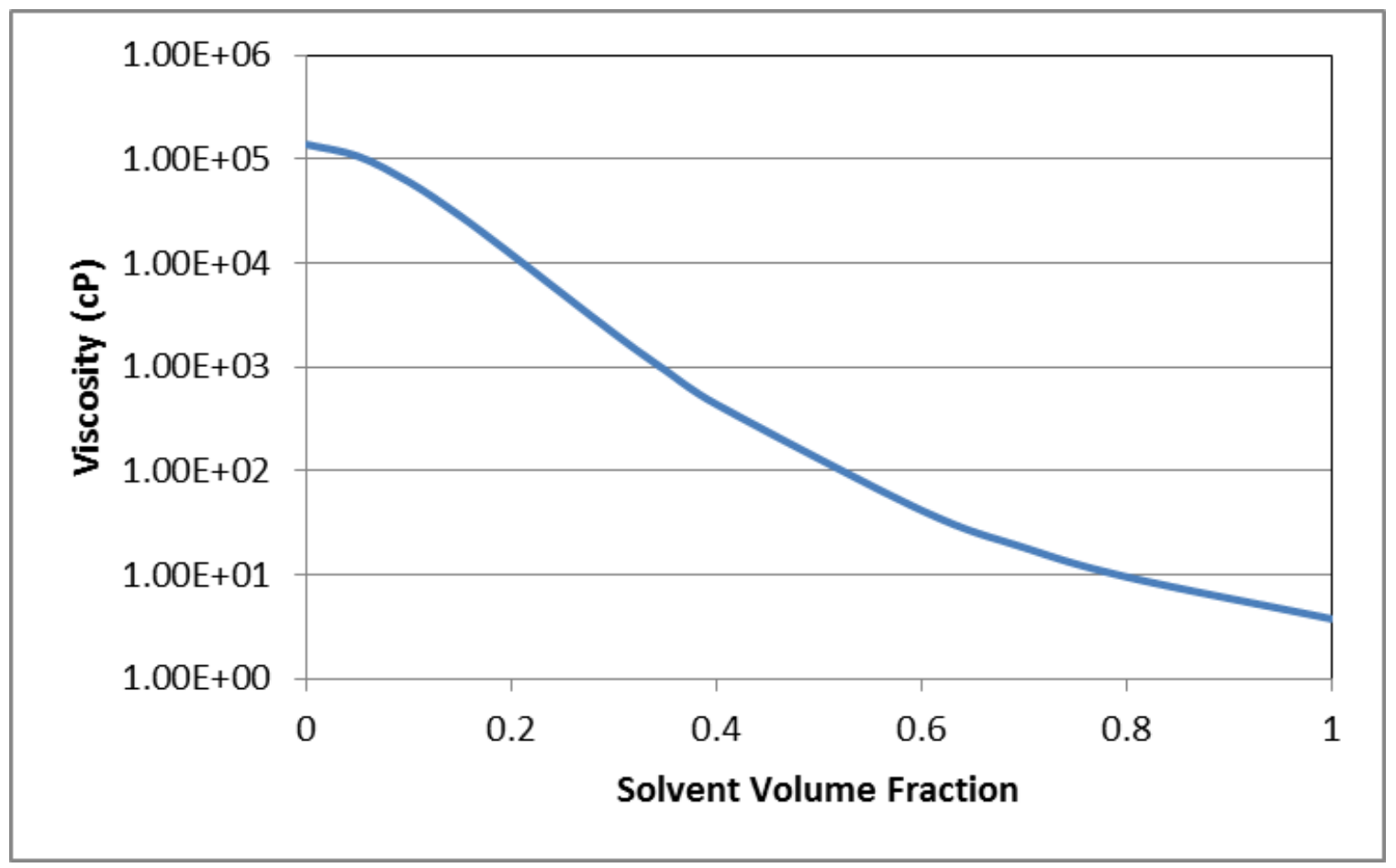

Fig. 10 - Semilog plot of a Cold Lake Bitumen blended with SCO as projected by the Barrufet-Setiadarma model 
At the viscosity of interest, $400 \mathrm{cP}$ as dictated by pipeline standards (Suncor Pipeline Company 2012), the model tells us that $41 \%$ in weight of our blend is required to be SCO in order to meet transportation standards. As presented in section 3.2, the exact volume was $3,420 \mathrm{BBL} / \mathrm{D}$ of $\mathrm{SCO}$ at a cost of $\$ 366,000 / \mathrm{D}$.

\subsection{Visbreaking Simulation Results}

Given the visbreaking specifications of $300^{\circ} \mathrm{C}$ for 5 minutes, as given in section 3.1 , and the modeling scheme presented in the previous chapter, we are able to construct a specific model to determine the product of visbreaking a Cold Lake bitumen. Table 10 presents a sample visbreaking characterization the model provides.

The coke formation modeled from first order reaction kinetics in Eqs. 6 \& 7. provides $14 \%$ coke formed over five minutes. The rest of the products and their physical properties obtained as detailed in the previous chapter. Of particular note is the quantity of natural gas that we are flaring, as we will see later this can be potentially used to mitigate visbreaker operational costs. The light ends are characterized as a C20 alkane, while the heavy fraction is modeled from pre-existing literature on bitumens and bitumen residue (Alberta Research Council 2012). Both of these characterizations that form part of our "heavy-light fluid" are significantly more conservative than what these fractions might actually be characterized as. We also notice here that with the visbreaking severity as low as it is, we are minimizing conversion of light ends. This 
helps us to gauge the ability of the least lucrative scenario in terms of minimizing diluent use, and fits in well with our aim of creating a conservative model.

Table 10-PRODUCT OF VISBREAKING A COLD LAKE BITUMEN AT $300^{\circ} \mathrm{C}$ FOR 5 MINUTES

\begin{tabular}{|c|c|c|c|c|c|c|}
\hline Comp. & Description & $\begin{array}{c}\text { Mass } \\
\text { (tonne) }\end{array}$ & $\begin{array}{c}\text { Weight } \\
\%\end{array}$ & $\begin{array}{l}\text { Density } \\
(\mathrm{g} / \mathrm{cm} 3)\end{array}$ & $\begin{array}{l}\text { Vol. } \\
\text { (bbl) }\end{array}$ & $\begin{array}{c}\text { Viscosity } \\
\text { (cP) }\end{array}$ \\
\hline Original & & 811 & & & & \\
\hline Oil & CL Bitumen & & 1 & 1.002 & 5000 & $1.4 \mathrm{E}+05$ \\
\hline Gas & Methane & 16 & 0.02 & 0.00068 & $825 \mathrm{Mscf}$ & - \\
\hline Light & $\mathrm{n}-\mathrm{C} 20$ & 162 & 0.20 & 0.862 & 1183 & 8 \\
\hline Heavy & Residue & 522 & 0.64 & 1.018 & 3226 & $9.0 \mathrm{E}+05$ \\
\hline Coke & Solid & 110 & 0.14 & - & - & - \\
\hline $\begin{array}{c}\text { Heavy- } \\
\text { Light } \\
\text { Fluid }\end{array}$ & $\begin{array}{l}\text { Saleable } \\
\text { Product }\end{array}$ & 684 & 0.84 & 0.976 & 4409 & $3.7 \mathrm{E}+04$ \\
\hline
\end{tabular}

Of particular note is the reduction of viscosity that even a minimum conversion brings. The original oil has a viscosity of around 140,000 $\mathrm{cP}$ while the visbroken light-heavy mixture, which we will subject to further blending, has a viscosity of around 37,000 cP, almost a whole order of magnitude lower. It is worthwhile to mention again at this juncture that the final mixture viscosity is obtained by using the Barrufet-Setiadarma blending model on the heavy and light fractions. 
The heavy-light mixture is then put through the dilution model presented in Section 4.1 to gauge the reduction of diluent as a result of visbreaking. Fig. 11. presents the outcome of this operation.

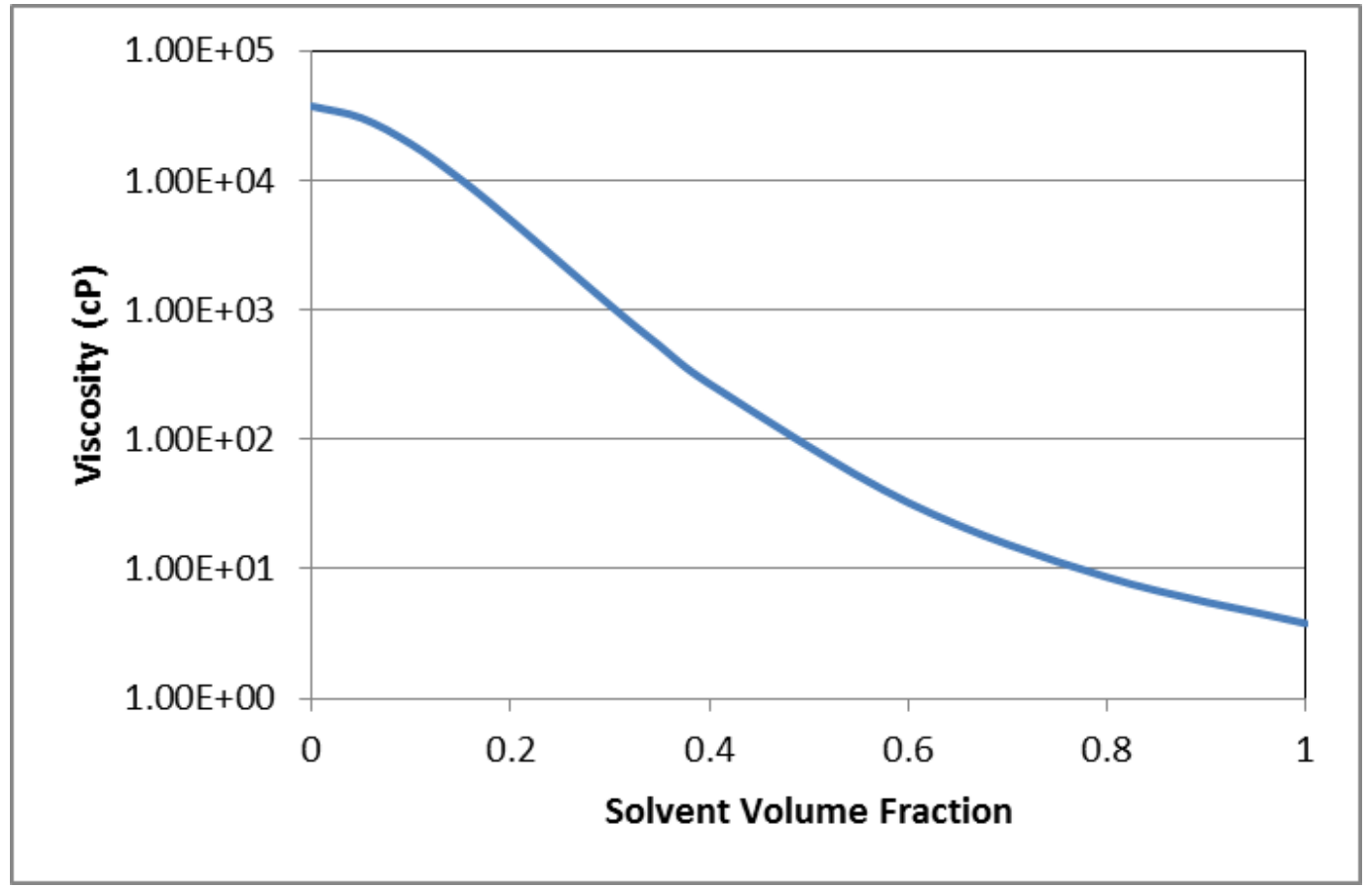

Fig 11—Cold Lake bitumen product post-visbreaking blended with SCO as projected by the Barrufet-Setiadarma model

Compared to Fig. 9., we can see that the transportation viscosity of $400 \mathrm{cP}$ is reached at approximately $37 \%$. Taking into account the reduction in the volume of visbroken fluid, the required volume of SCO diluent after visbreaking is 2,589 BBL/D, which corresponds to a diluent cost of about $\$ 277,000 / \mathrm{D}$. Obviously we are not quite comparing apples to apples yet, however the next section will clarify this discrepancy. 


\subsection{Economics}

The objective of this section is to investigate the economic impact of visbreaking at the source, i.e. the benefit that visbreaking adds to the producer. First, we will list some cost assumptions we make for this section. Table $\mathbf{1 1}$ details this.

Table 11-COST ASSUMPTIONS FOR THE ECONOMIC MODEL

\begin{tabular}{|c|c|c|}
\hline Parameter & Definition & Source \\
\hline Diluent Price (SCO) & $\$ 107 / \mathrm{BBL}$ & Dec '11 Spot Price \\
$\begin{array}{c}\text { Visbreaker CAPEX } \\
\text { for 'X' BBL/D }\end{array}$ & $(\mathrm{X} / 10,000)^{0.7} \mathrm{x}(21,000,000)$ & $\begin{array}{c}\text { Ventech Report Scaled on a } \\
10,000 \mathrm{BBL} / \mathrm{D} \text { basis }\end{array}$ \\
$\begin{array}{c}\text { Cost of Maintenance } \\
\text { Cost of Natural Gas }\end{array}$ & 10 cents/BBL & Wiehe (2010) \\
\hline
\end{tabular}

The diluent price and the natural gas price values are fairly self-explanatory. Natural gas is the fuel we use for visbreaker operations. The visbreaker capital expenditure is obtained from the Ventech report cited earlier. The cost of a visbreaker is given as $\$ 21,000,000$ for a $10,000 \mathrm{BBL} / \mathrm{D}$ visbreaker. The equation listed in the definition of the CAPEX applies a scaling factor prescribed by Ventech as an accurate estimation which makes it suitable for our purposes. ' $\mathrm{X}$ ' is the desired size of the visbreaker, with 10,000 $\mathrm{BBL} / \mathrm{D}$ being the maximum possible capacity and 2,000 BBL/D being the minimum. Since our operations are limited to small and medium size operators, the equation can be accepted with reasonable degree of credulity without the prospect of worrying unduly 
about scaling errors. The maintenance cost is difficult to estimate, and also should have a scaling factor. Wiehe states that maintenance of equipment in refineries costs in between 2-10 cents a barrel in personnel time and downtime. We use the upper limit of this estimate as the maintenance cost for visbreaking, in keeping with our objective of conservative modeling. The cost of natural gas is used to calculate the operational costs of the visbreaker and is scaled linearly based on a 10,000 BBL/D visbreaker utilizing 27 MMBTU of energy/hr. Now, as shown in Table 10, visbreaking 5000 BBL/D of CL bitumen results in the production of $825 \mathrm{Mcf} / \mathrm{D}$ of gas. Since the caloric value of natural gas is roughly $1,000 \mathrm{BTU} / \mathrm{scf}$, the amount of natural gas produced from visbreaking should be more than sufficient to cover the energy requirements of the visbreaker every day. While this might result in additional top end capital costs the overall result would be that the visbreaker operates without any operational expenditure. For our analysis however, we will assume that all the gas is flared, in order to give ourselves a conservative economic scenario.

\subsubsection{Case Specific Results}

For our case of a 5,000 BBL/D Cold Lake Bitumen, Table 12 gives a brief rundown of the numbers of the economic comparison of visbreaking. 
Table 12-ECONOMICS FOR THE VISBREAKING OF A 5000 BBL/D COLD

LAKE BITUMEN PRODUCTION FACILITY

\begin{tabular}{|l|c|c|}
\hline \multirow{2}{*}{ CAPEX } & Dilution & Visbreaking \\
\cline { 2 - 3 } OPEX & - & $\$ 12,927,016$ \\
--Total Cost (/D) & $\$ 366,000$ & $\$ 276,400$ \\
-- Cost of diluent (/bbl product sold/D) & $\$ 43.46$ & $\$ 39.58$ \\
-- Cost of maintenance (/D) & - & $\$ 500$ \\
-- Other Operational Costs (/D) & - & $\$ 1,717$ \\
-- Total OPEX (/bbl product sold/D) & $\$ 43.46$ & $\$ 39.90$ \\
\hline
\end{tabular}

The CAPEX is scaled based on the equation in Table 11. The cost of diluent is represented as per barrel of product sold per day. This is the amount of diluent used divided by the entire product shipped through the transportation pipeline. The effect of the visbreaking is clear here, there is almost a $\$ 4 / \mathrm{BBL}$ reduction in the amount of diluent used at the source. Effectively then, we are to confirm that the cost needed to operate the visbreaker will be less than $\$ 4 / \mathrm{BBL}$. The cost of maintenance is ten cents a day per barrel produced, while the operational cost is the natural gas needed to heat the bitumen to $300^{\circ} \mathrm{C}$. Just to recap the data from the Ventech report earlier, the case in that report says that the operating costs for a visbreaker are less than $\$ 1 / \mathrm{BBL}$. That result is corroborated here. 
In order to model NPV over 10 years based on Eqs. 8-11, we must apply some sort of decline rate scenario to our analyses. We assumed a simple Arps exponential decline with the following parameters:

$\mathrm{q}_{\mathrm{i}}=5000 \mathrm{BBL} / \mathrm{D}$

$\mathrm{t}=10$ years

$\mathrm{q}=2000 \mathrm{BBL} / \mathrm{D}$

where $\mathrm{q}_{\mathrm{i}}$ is the initial production rate, $\mathrm{t}$ is the economic time limit of 10 years and $\mathrm{q}$ is the rate at the economic limit which is set at a value assumed to be the threshold for a medium size operator relevant to our study.

Now, a basic Arps exponential decline is presented in Eq. 12.

$$
\frac{q}{q_{i}}=\frac{1}{e^{D t}}
$$

where $\mathrm{D}$ is the Arps exponential decline rate, a constant. Using the parameters given above we find

$\mathrm{D}=0.000251039 / \mathrm{D}$

Using the Arps decline and Eqs. 8-11 for differential NPV discounted at 11\% we are able to generate Table $\mathbf{1 3 .}$ 


\section{Table 13-SAMPLE DIFFERENTIAL NPV CALCULATION FOR A CL BITUMEN PUT THROUGH THE CODE}

\begin{tabular}{|l|l|l|l|}
\hline Year & Production Rate & Cash Flow & d(NPV) \\
\hline 0 & 5000 & $-\$ 13 \mathrm{MM}$ & $-\$ 13 \mathrm{MM}$ \\
2 & 4562 & $\$ 8 \mathrm{MM}$ & $-\$ 5 \mathrm{MM}$ \\
3 & 3798 & $\$ 8 \mathrm{MM}$ & $\$ 1 \mathrm{MM}$ \\
4 & 3466 & $\$ 7 \mathrm{MM}$ & $\$ 5 \mathrm{MM}$ \\
5 & 3162 & $\$ 6 \mathrm{MM}$ & $\$ 9 \mathrm{MM}$ \\
6 & 2885 & $\$ 6 \mathrm{MM}$ & $\$ 12 \mathrm{MM}$ \\
7 & 2633 & $\$ 5 \mathrm{MM}$ & $\$ 15 \mathrm{MM}$ \\
8 & 2402 & $\$ 5 \mathrm{MM}$ & $\$ 17 \mathrm{MM}$ \\
9 & 2192 & $\$ 4 \mathrm{MM}$ & $\$ 19 \mathrm{MM}$ \\
\hline 10 & 2000 & $\$ 4 \mathrm{MM}$ & $\$ 20 \mathrm{MM}$ \\
\hline
\end{tabular}

Clearly then, this conservative preliminary screening says that visbreaking has obvious advantages over blending. However, we must now examine whether capital costs are mitigated within a sufficient period and whether the long term prospects of visbreaking are still positive. To keep the analysis simple, the capital costs are deducted up front at year 1. There are no incentives that occur due to depreciation or taxation. This allows to 
to create comparisons for costs and energy drives and add another dimension to our conservative modeling.

We discount the cash flow at $8 \%$ and $11 \%$, the results are presented in Fig. 12.

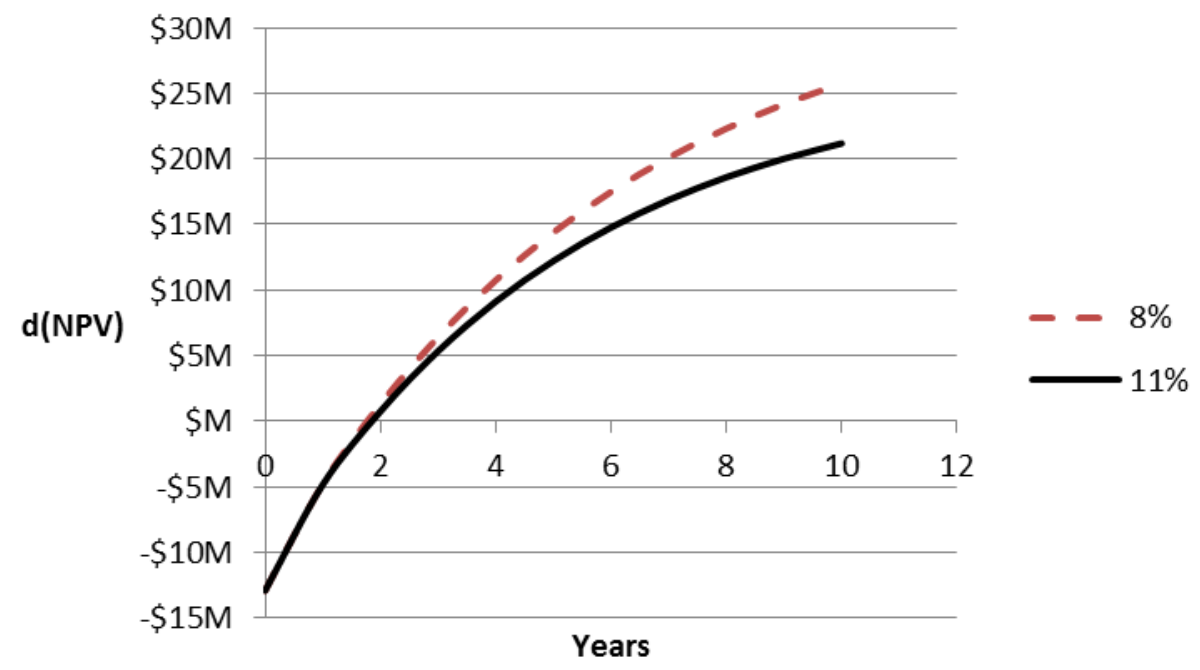

Fig 12-Differential NPV with $8 \%$ and $11 \%$ discounting rate projected over 10 years

As we can see from the figure the $\$ 4 / \mathrm{BBL}$ shown in Table 12 savings result in extremely rapid payback periods of around 2 years. Over a ten year period, we see that the payoffs are in excess of $\$ 20 \mathrm{M}$. We can say quite confidently that a combined visbreaking and blending operation distinguishes itself as a more viable option to blending alone. For our future analyses of cost and energy drivers, we will use the $11 \%$ NPV discount rate. 


\subsection{Cost and Energy Drivers of Differential NPV}

Knowing the effectiveness of the base model, we can expand upon what drives the positive economics of this model. The model we have created is flexible enough and robust enough in order to run multiple sensitivities that divulge vital information on the cost and energy drivers of our operation. Prior to embarking upon this study we reiterate that the black solid line in each of the subsequent graphs represents the case used in our sample calculation. Put simply, this is a $5000 \mathrm{BBL} / \mathrm{D}$ Cold Lake bitumen production facility that is diluted with $\mathrm{SCO}$ and visbroken at $300^{\circ} \mathrm{C}$ for 5 minutes.

The diluent price is the major distinguisher between blending and visbreaking. Fig. 13. shows the variation of the differential NPV as a function of diluent price.

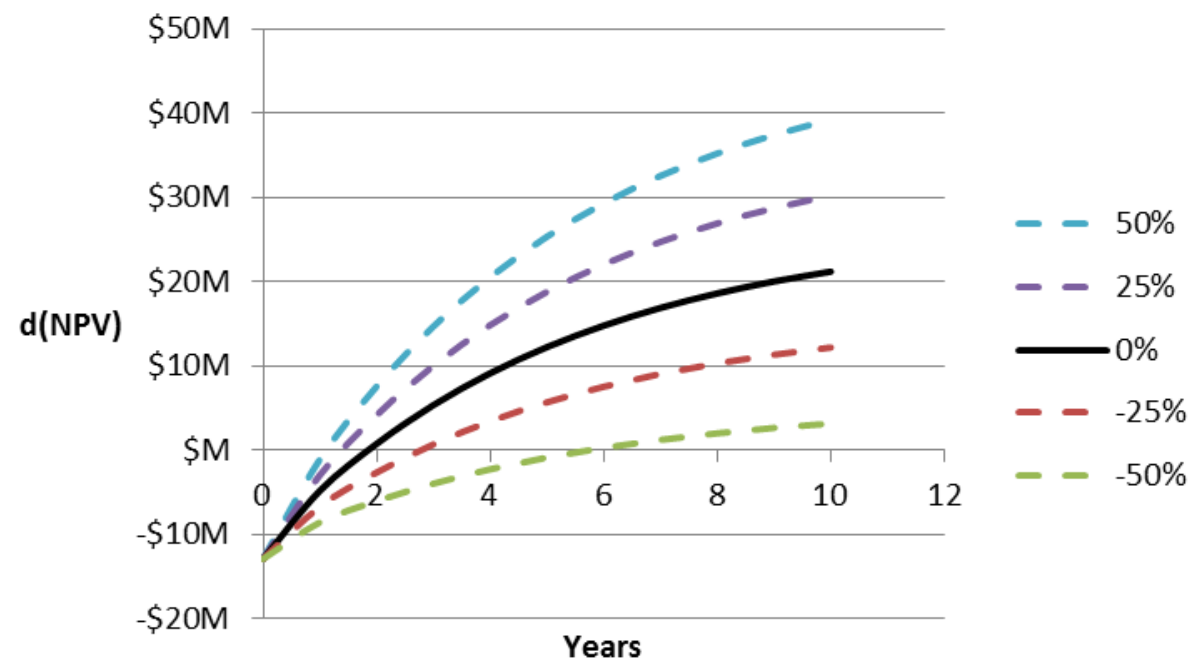

Fig 13-Differential NPV as a function of diluent price. The base case is SCO @\$107/BBL 
The variation in the payback periods immediately leaps to the eye. Even a 50\% reduction in diluent price leads to a positive outcome over a ten year period. However, much longer payback periods and an insubstantial increase in eventual NPV might discourage capital investment on the part of the producer. Thus, diluent price plays a large part in determining whether partial upgrading is the way to go. That said, it is important to note that the price of oil and the price of diluent often go hand in hand. Therefore, lower diluent prices imply lower oil prices and since the production of heavy oil is heavily dependent on the market, lower diluent price may also imply that the market is not conducive enough to heavy oil production in the first place.

The variability in NPV given different diluents is of further interest. Fig. 14 illustrates these changes.

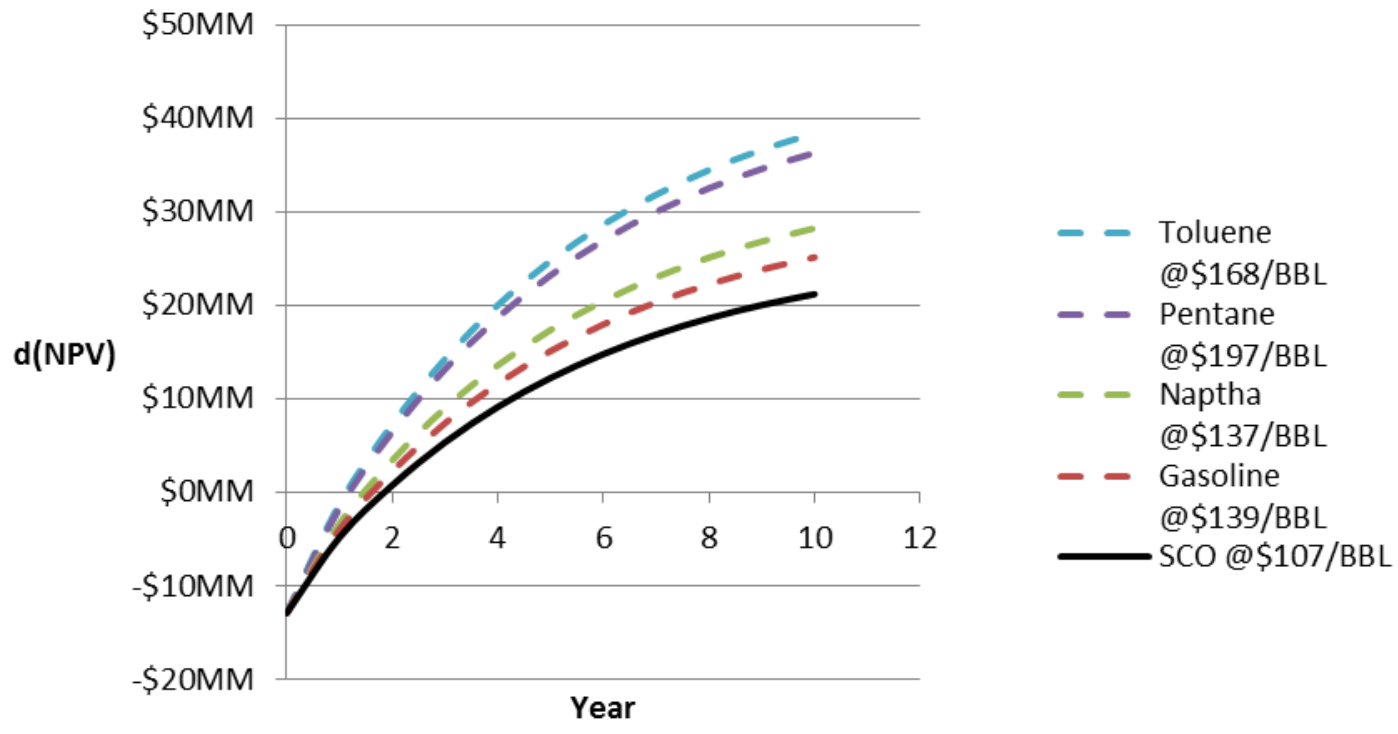

Fig 14-Change in Differential NPV with Type of Diluent 
Clearly, we can see that SCO is the least efficient diluent in terms of price. Incidentally, this is also true for SCO in terms of volume. However, this fact does not apply across the board. Pentane is the most efficient diluent in terms of reduction of volume, however that does not translate to the best NPV. This graph is particularly revealing since it reinforces the need for blending models. We must keep in mind however, that the diluent costs presented here are only based on the market price for each diluent. This does not include the costs based on availability or pipelining costs. While SCO is clearly the least profitable diluent, it is readily available at upgrading facilities and still may be the diluent most suitable for use on a project. The factors outlined in Chapter II regarding diluent selection become all the more relevant with this graph.

We have determined that the operational costs of the visbreaker are less than $\$ 1 / \mathrm{BBL}$. Therefore we would expect that the drivers relating to this cost to not produce as dramatic a variation as the price of diluent. This is confirmed with Fig. 15. 


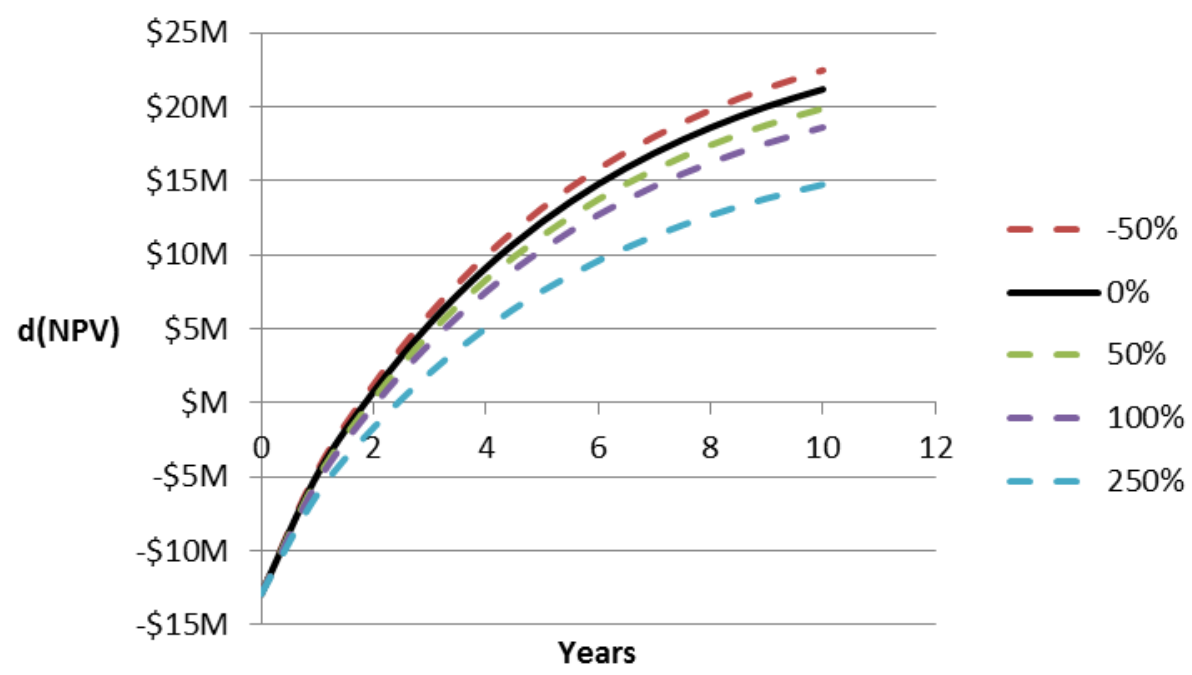

Fig 15-Differential NPV as a function of natural gas price. The base case is

\section{\$3.05/MMBTU}

Even a natural gas price two and a half times the one used in the initial analysis does not yield a major change in NPV. Coupled with the previous graph, this implies a powerful message that not only is partial upgrading economically beneficial, to an extent it immunized itself somewhat to market forces. The volatility that we experience as a result of dependence on spot prices of oil and diluent are dulled due to a decrease in the use of market dependent diluent prices. This is a somewhat intangible benefit that nevertheless deserves mention.

Having looked at some of the cost drivers of the process, we turn now to the energy drivers in the process, namely the visbreaking temperature and time. Figs. $16 \& 17$ illustrate the effects upon differential NPV of visbreaking temperature and time respectively. 


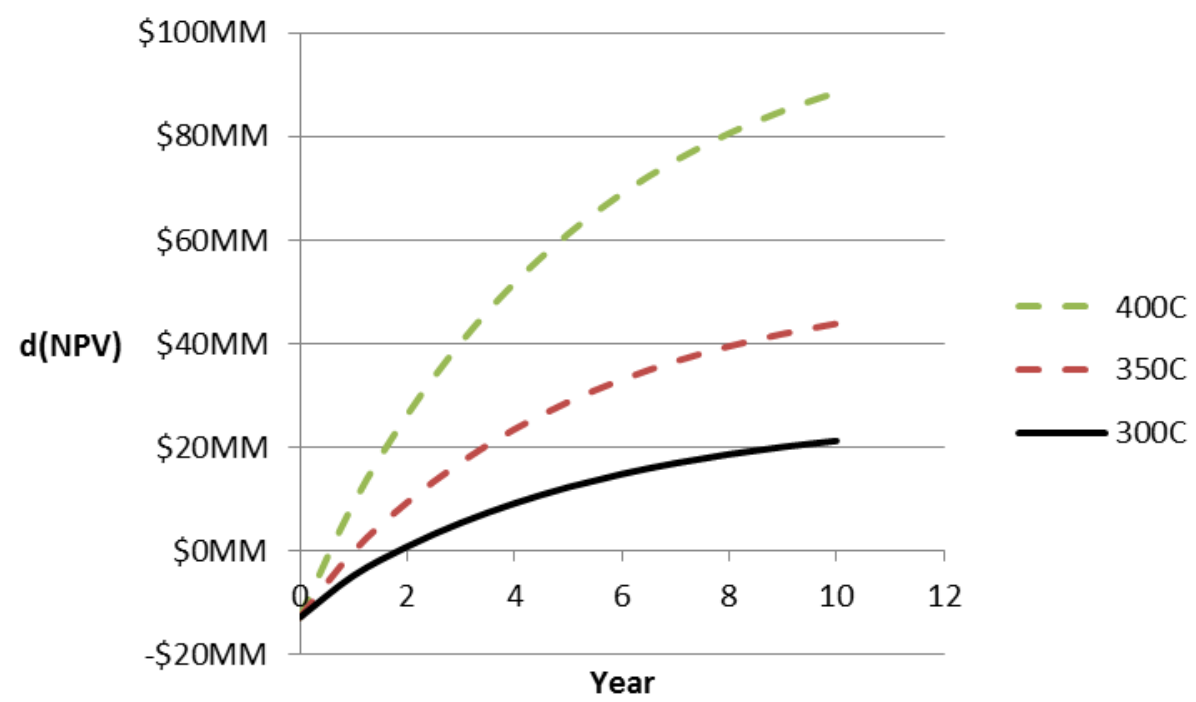

Fig 16-Differential NPV as a function of visbreaking temperature, with time held constant at 5 minutes

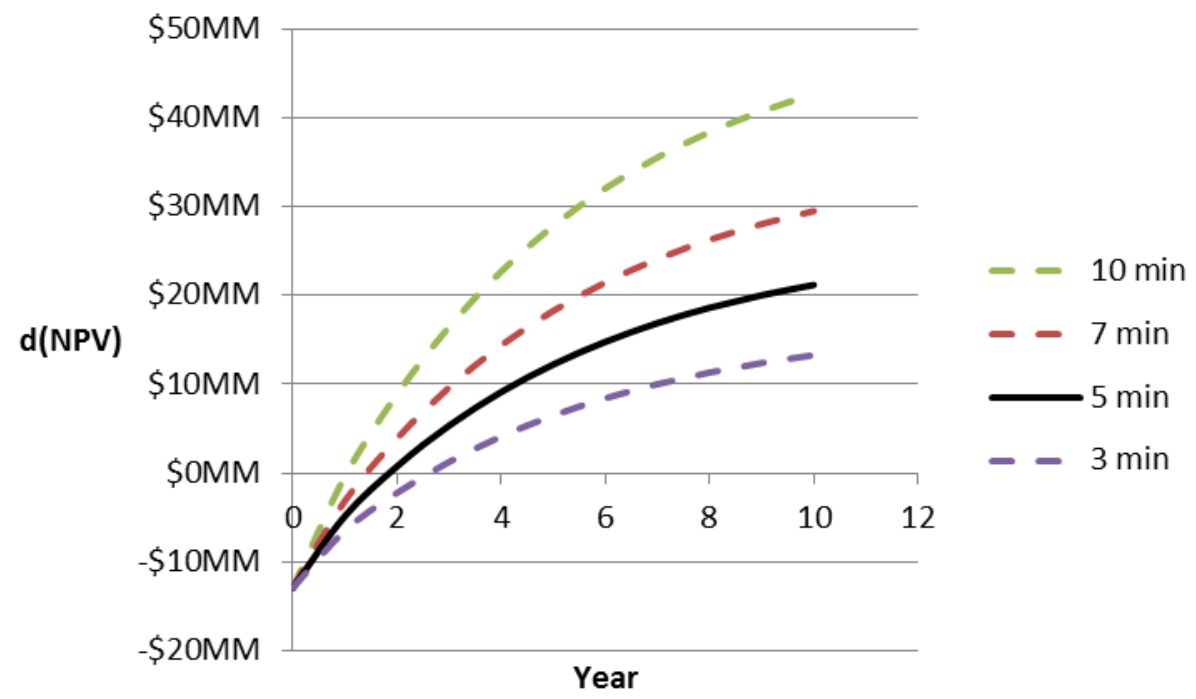

Fig 17-Differential NPV as a function of visbreaking time, with temperature held constant at $300^{\circ} \mathrm{C}$ 
The visbreaking temperature is a major motivator in the increase of NPV. This corroborates our projection that conversion into valuable light ends far outstrips the disadvantages of coke disposal. Increasing in visbreaking times also increases the NPV although the increase is certainly not as dramatic as the increase observed through increasing temperature.

Finally, we can take a look to see how our conservative simulation of viscosity reduction in the visbreaker affects economics. Fig. 18. represents the effects of more liberal characterizations of light ends

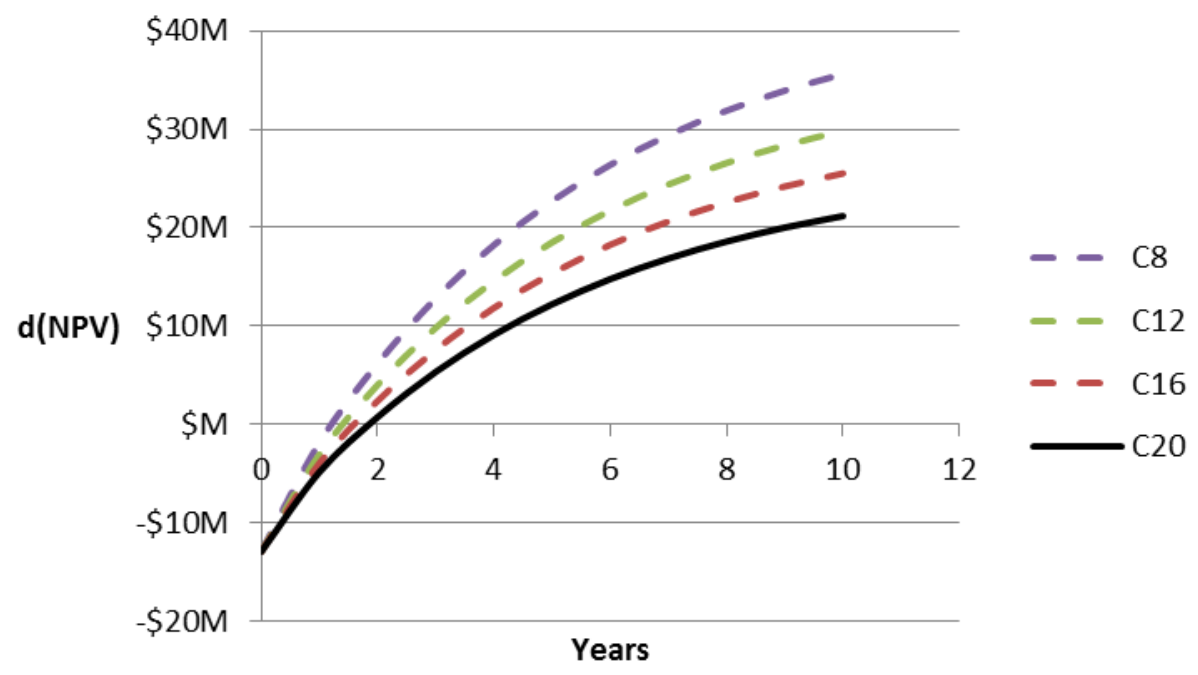

Fig 18-Differential NPV as a function of light ends characterization

Again, there are significant differences with payback periods and NPV. C8 is usually more of a typical light ends characterization; this shows that the potential of visbreaking 
might be higher than predicted with our model. However, the primary drivers of the economics remain diluent price and visbreaking severity.

\subsection{Value Chain Analyses}

Let us first quickly recap Porter's terminology on value chains. Porter says "a systematic way of examining all the activities a firm performs and how they interact for analyzing the sources of competitive advantage". The value chain here extends from producer through the mode of transportation and terminating at the refinery. This section will provide some insight on the potential of adding value to the producer that may have an economic interest in midstream and downstream operations.

\subsubsection{PIPESIM Analysis}

As mentioned earlier, we used a PIPESIM black oil model to simulate pipeline transportation. The software tool that we have created provides the user with input data for this black oil model. The table characterizes the oil viscosity at various temperatures and enables the PIPESIM program to create a viscosity model for a particular oil. Since PIPESIM is not able to handle heavy oils through built in viscosity characterizations, this step is essential. The table is generated as a result of running the BarrufetSetiadarma model on the combination of oils and solvents at various temperatures. PIPESIM requires a minimum of two data points for a viscosity characterization; our code provides nine data points for a well-defined viscosity model. Furthermore, the 
pipeline is assumed insulated, ensuring that the temperature does not vary significantly for the duration of the run.

Having created a PIPESIM model, we can then build a pipeline system that accurately represents the transportation. Fig. 19. shows a simplified pipeline system that simulates 250 mile transportation from a producer to a refinery.

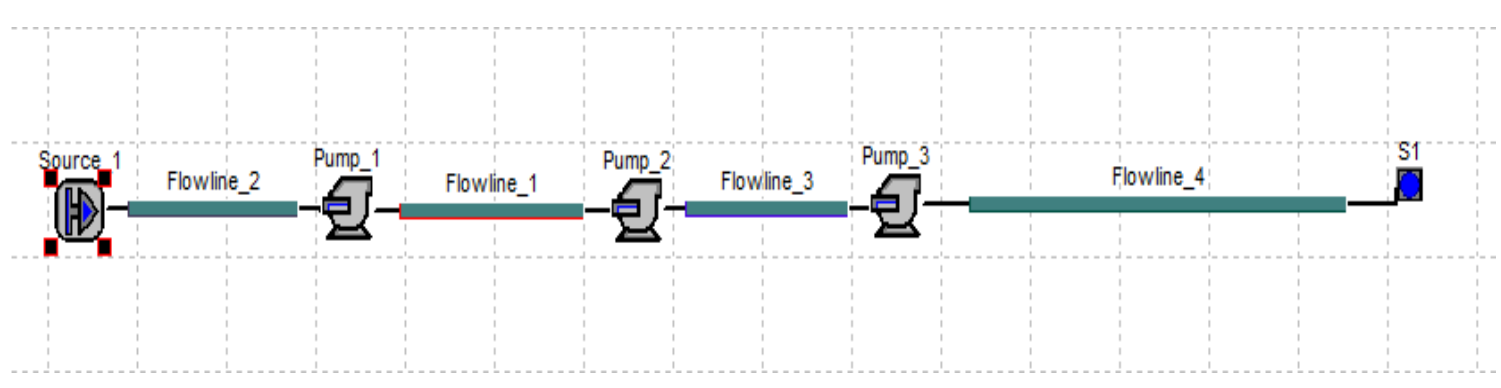

Fig 19-A typical PIPESIM transportation system

There are pumping stations at routine intervals that boost transportation pressure to keep up with pipeline specification pressures, which vary depending on the contract between the pipeline company and the producers. Normally, heavy oils are transported at very high pressures, often in excess of 1000 psi. The pipeline pressures are usually kept at within a certain acceptable range, depending on the throughput desired and the ability to maintain fluid stability. For this analysis we use 1000 psi as the maximum cutoff for pipeline safety and $750 \mathrm{psi}$ as the minimum cutoff to maintain flow assurance. We assume the pipeline is completely thermally insulated and has no undulations, i.e. it is completely horizontal and has a constant diameter. As a result, the difference in pressure 
drops we observe is purely a result of a frictional pressure drop. Fig. 20 gives us a detailed pressure profile from the initial 1000 psi pressure to the distance travelled until the minimum threshold is reached.

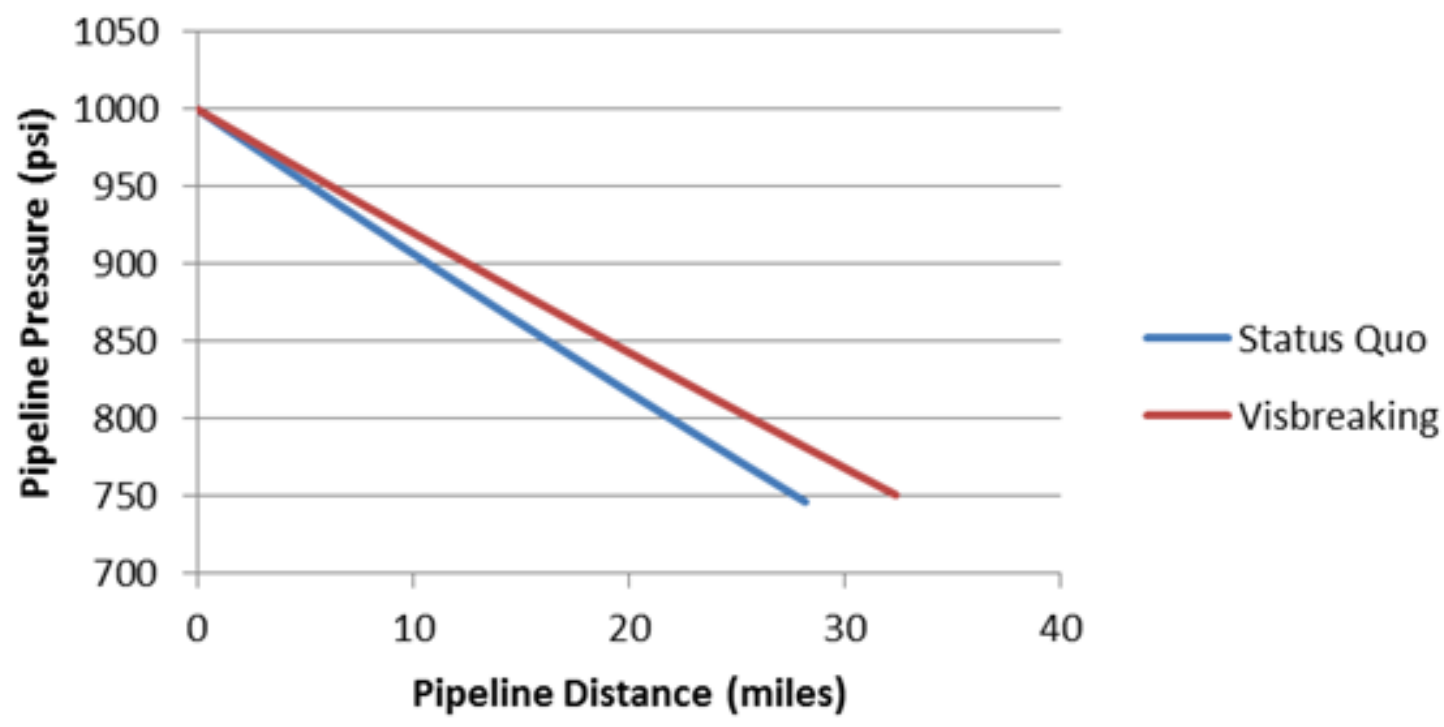

Fig. 20-Pipeline pressure drops for both our scenarios

For both the above scenarios the pipe diameter is kept constant at 12.5 in, while the flow rate is set at $8420 \mathrm{BBL} / \mathrm{D}$, which is the combined flow rate of the oil and solvent in our baseline dilution case. Assuming we were to not cap oil production at $5000 \mathrm{BBL} / \mathrm{D}$ as in our example case, Table 14 shows the potential excess oil and less diluent that we are able to transport through the pipeline in our example as a result of visbreaking. The fraction of oil in the blend is calculated through our earlier blending model analyses. Clearly, visbreaking has a significant advantage, and is able to transport almost $7 \%$ 
excess oil through the pipeline every day. All other pipeline dimensions like roughness, pipe material are kept the same for both cases.

Table 14-EXCESS SALEABLE OIL TRANSPORTED AS A RESULT OF VISBREAKING

\begin{tabular}{|c|c|c|}
\hline & Blending Only Case & Visbreaking Case \\
\hline Total Vol. of Blend (BBL/D) & 8420 & 8420 \\
\cline { 1 - 1 } \% of Oil in Blend (fraction) & 0.59 & 0.63 \\
\cline { 1 - 1 } Vol. of Oil in Blend (BBL/D) & 5000 & 5309 \\
\hline
\end{tabular}

We can see that the visbroken product has an advantage of being able to transport the same volume of fluid about 30 miles for every 24 miles of the heavier non-visbroken product within same the pressure range. Typically distances to a refinery are easily a few hundred miles. Using the numbers from our analysis we see that for every 150 miles, the visbroken product requires the use of one less booster station.

We must make some important points at this juncture. We have so far specified a "transportation viscosity" of $400 \mathrm{cP}$. This helped standardize our economic analysis. In reality, viscosity is regulated in pipelines, in large part, through pipeline temperature. Therefore, the two fluids we are comparing would have different viscosity temperature profiles. Obviously, if the viscosity were a standard value of $400 \mathrm{cP}$, there would not be 
a difference in the frictional pressure drops. However, were the pipeline not horizontal, there would certainly be a difference in hydrostatic pressure drops. Furthermore, this example does not provide ideal flow assurance. In our case the product piped through is less than $10,000 \mathrm{BBL} / \mathrm{D}$ for a 12 in pipeline at a range of 750-1000 psi. Running a simple Hagen-Poiseuille equation will tell us this pipeline is capable of transporting a much higher volume throughput. Additionally, the analysis has several permutations in terms of length and diameter of the pipeline, the material used to construct pipelines, the types of pump stations used and the points where diluent is added. Given that these variables are plentiful and an exact economic outcome depends on several possibilities, it would be churlish to put a dollar value on this analysis. That said, the message in Fig. 20 is clear: a less dense and less viscous oil will have lower pressure drops in a pipeline system thus enabling us to transport either larger volumes or longer distances.

\subsubsection{Refinery Concerns}

The final destination of our oil may also play an important part in our decision making. This section shall not provide any detailed analysis on the case we have presented, however it will provide some data that, from a macro-economic point of view, is worth mentioning. Since refinery data worldwide can be limited, we will concentrate mainly on refineries within the United States and heavy oil production from Canada for this analysis. The National Energy Board (NEB) in Canada estimates that $427 \mathrm{MMBBL}$ of heavy oil was produced in Canada in 2010, from this roughly 128 MMBBL was upgraded synthetic crude oil (2011). The NEB also has detailed data on the export of oil 
to US refineries during this time. That data is listed in Table 15. Fig. 21. details the areas within the United States that are referenced within the preceding table.

Table 15-DAILY CANADIAN HEAVY OIL EXPORTS TO THE USA IN 2010

(National Energy Board 2011)

\begin{tabular}{|c|c|c|c|c|}
\hline & Conventional & Blended & Total & Canadian \\
Destination & Heavy & Bitumen & Thermal Cracking \\
& (BBL/D) & (BBL/D) & Exports & Capacity (BBL/D) \\
\hline US PADD 1 & $18,047.3$ & $1,372.9$ & 19,420 & 49,000 \\
US PADD 2 & $431,699.8$ & $414,030.0$ & 845,730 & 411,000 \\
US PADD 3 & $40,765.9$ & $91,604.6$ & 132,370 & $1,464,200$ \\
US PADD 4 & $114,645.9$ & $43,322.9$ & 157,970 & 88,100 \\
US PADD 5 & - & $46,321.7$ & 46,320 & 619,200 \\
US Total & $605,158.9$ & $596,652.1$ & $1,201,800$ & $2,631,700$ \\
\hline
\end{tabular}




\section{Petroleum Administration for Defense Districts}

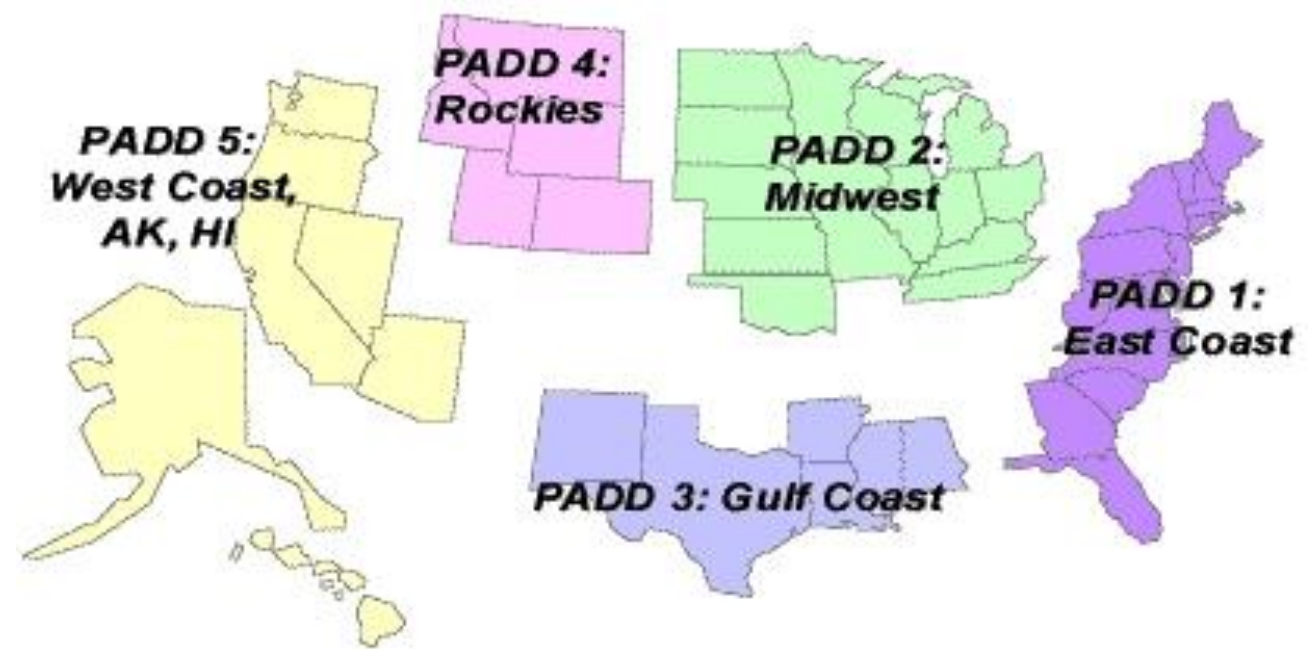

Fig 21—US Refinery Regions (National Energy Board 2011)

As we can see, the exports to the Midwestern United States make up most of the exports of heavy oil from Canada. Midwestern refiners are devoting all of their thermal cracking capacity to heavy crude from Canada. Additionally, the Rocky Mountain regions are taking in far more than they are able to thermally crack. In contrast, the Gulf Coast and the West Coast have extensive thermal capacities but comparatively much lower imports. The proposed Keystone XL pipeline hopes to route some of these exports to the Gulf Coast region, a distance of nearly 2000 miles from the producer. The possibility of dealing which such large distances makes the analysis of the preceding section all the more relevant. Fig. 22. is a visual representation of the discrepancies in thermal cracking, which sheds some light on why this project is being proposed (Energy Information Administration 2011). 


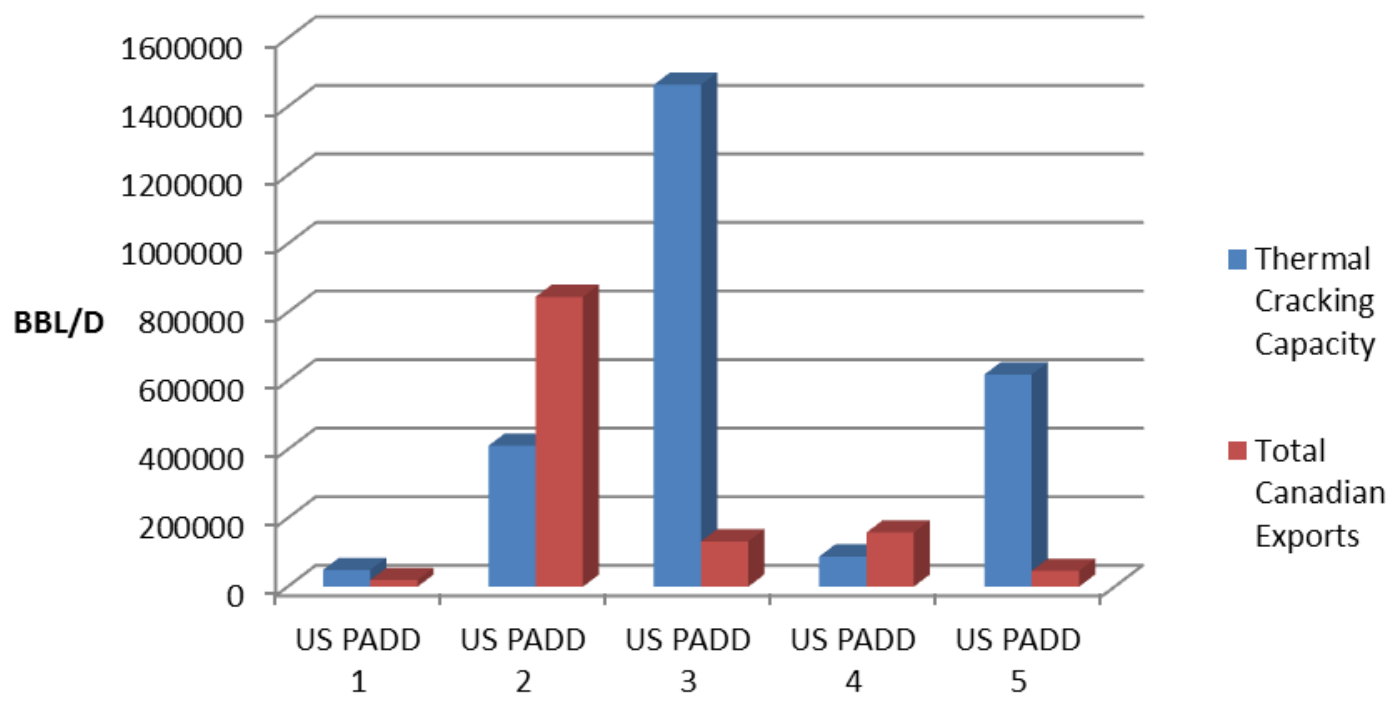

Fig 22-Thermal cracking capacity of US refineries

Heavy oils usually require some sort of thermal cracking operations in order to be converted into viable product. The Gulf Coast clearly has the highest capacity to perform these operations. The Midwest refineries are clearly not equipped to handle larger volumes than are already being exported. Additionally, most refineries in the United States are already overwhelmed and operating at maximum capacity, which means that alternatives to simply transporting blended bitumen must be found. An interesting twist and counterpoint to this claim is that the refineries are major suppliers of products such as naphtha, which find prolific use as diluents in the heavy oil industry. The answer then, to whether partial upgrading benefits this end of the value chain is not a clear one. In fact 
this information, coupled with the transportation question, makes it clear that value chain analyses may not be easily subject to standardization and needs further research. 


\section{CONCLUSIONS AND RECOMMENDATIONS}

- We have created a robust and flexible screening test that identifies the economic benefits of visbreaking to the producer. The test is based on conservative reaction kinetics and economic assumptions which proves a worthwhile preliminary tool that may be used for screening a potential partial upgrading project

- The test is viable for specific built in and user defined heavy oils and solvent. Thus, it manages to achieve standardization in modeling that is notoriously difficult to achieve with heavy oils

- Our sample case study shows that visbreaking has low operational and maintenance costs, less than $\$ 1 / \mathrm{BBL} / \mathrm{D}$, and sufficiently mitigates diluent cost to provide short payback periods. In addition, for small and medium size operators it is able to lower operating costs by $\$ 3.50 / \mathrm{BBL} / \mathrm{D}$

- The primary cost driver of visbreaking is the cost of diluent. Lower diluent costs may provide longer payback periods that discourage capital investment. However, visbreaking is less volatile to market conditions.

- The value chain implications of visbreaking are striking. Visbreaking gives a less dense, less viscous oil for transportation. This translates to lower pressure drops during pipeline transportation which allows transportation of larger volumes, longer distances or savings on capital expenditure on pipes and pumping stations. 
- This model is not comprehensive. A positive test with this model is only an endorsement that investment into a thorough investigation of partial upgrading is a worthwhile endeavor. 


\section{REFERENCES}

Agroskin, A.A.A., E. V.; Goncharov, E. I.; Tyagunov, V. M.; Valyavin, G. G. 1978. Thermochemical Characteristics of Petroleum Residuum Coking. Chemistry and Technology of Fuels and Oils 14 (6): 412-415.

Alberta Research Council. Annual Report of the Research Council of Alberta. 1943. Edmonton, Alberta.

Argillier, J.-F., Henaut, I., gateau, p. et al. 2005. Heavy-Oil Dilution. Paper presented at the SPE/PS-CIM/CHOA International Thermal Operations and Heavy Oil Symposium, Calgary, Alberta, Canada. 97763. DOI: 10.2118/97763-ms.

Aspen Hysys. Aspen Technology. http://www.aspentech.com/hysys/. Accessed $07 / 25 / 2012$

Banerjee, D.K., Laidler, K.J., Nandi, B.N. et al. 1985. Kinetic Studies of Coke Formation in Hydrocarbon Fractions of Heavy Crudes. Fuel 65: 480-484.

Barrufet, M.A. and Setiadarma, A. 2003. Reliable Heavy Oil-Solvent Viscosity Mixing Rules for Viscosities up to $450 \mathrm{k}$, Oil-Solvent Viscosity Ratios up to $4 \times 105$, and Any Solvent Proportion. Fluid Phase Equilibria 213 (1-2): 65-79. DOI: $10.1016 / \mathrm{s} 0378-3812(03) 00285-1$

Bennison, T. 1998. Prediction of Heavy Oil Viscosity. Paper presented at the IBC Heavy Oil Field Development Conference, London.

Bozzano, G., Dente, M. and Carlucci, F. 2005. The Effect of Naphthenic Components in Visbreaking Modeling. Computers \& Chemical Engineering 29 (4): 1439-1446. 
Clark, W., Graves, G.W., Lopez-de-Cardenas, J.E. et al. 2007. Heavy Oil. Washington, D.C.: National Petroleum Council.

Egbogah, E.O. and Ng, J.T. 1990. An Improved Temperature-Viscosity Correlation for Crude Oil Systems. Journal of Petroleum Science and Engineering (5): 197-200.

Energy Information Administration. Refinery Capacity Report. http://www.eia.gov/petroleum/refinerycapacity/. 2011

Flint, L. 2004. Bitumen and Very Heavy Crude Upgrading Technology. LENEF Consulting Ltd.

Fukuyama, H., Nakamura, T.T., and Ikeda, A. 2010. Partial Upgrading of Bitumen at Sagd Wellsite. Paper presented at the Canadian Unconventional Resources and International Petroleum Conference, Calgary, Alberta, Canada. 136512.

Goshka, E.A. 2002. Diluent Supply/Demand and Alternatives for Heavy Oil. In: Purvin \& Gertz Inc.

Hayashitani, M., Bennion, D.W., Donnelly, J.K. et al. 1978. Thermal Cracking Models for Athabasca Oil Sands Oil. Paper presented at the SPE Annual Fall Technical Conference and Exhibition, Houston, Texas. 1978 Copyright 1978, American Institute of Mining, Metallurgical, and Petroleum Engineers, Inc. 00007549. DOI: $10.2118 / 7549-\mathrm{ms}$.

Henderson, J.H. and Weber, L. 1965. Physical Upgrading of Heavy Crude Oils by the Application of Heat. Jounal of Canadian Petroleum Technology OctoberDecember 1965: 206-212. 
Jaykumar, R. 2008. Analysis of Power Generation Processes Using Petcoke. Master of Science, Texas A\&M University.

Jooybari, H.S. 2012. A Novel Methodology for Simultaneous Estimation of Gas Diffusivity and Solubility in Bitumens and Heavy Oils. Paper presented at the SPE Heavy Oil Conference Canada, Calgary, Alberta, Canada. Society of Petroleum Engineers SPE-157734-MS. DOI: 10.2118/157734-ms.

Mehrotra, A.K., Patience, G.S., and Svrcek, W.Y. 1989. Calculation of Gas Solubility in Wabasca Bitumen. Journal of Canadian Petroleum Technology 28 (3). DOI: $10.2118 / 89-03-08$

Miadonye, A., Doyle, N., Britten, A., Latour, N. and Puttagunta, V.R. 2001. Modeling Viscosity and Mass Fraction of Bitumen - Diluent Mixtures. Journal of Canadian Petroleum Technology 40 (7): 52-57.

Motaghi, M., Saxena, P., and Ravi, R. 2010. Partial Upgrading of Heavy Oil Reserves. Houston: KBR Technology.

National Energy Board. Crude Oil and Petroleum Products Statistics. http://www.nebone.gc.ca/CommodityStatistics/Statistics.aspx?language=english/. 2011

Porter, M.E. 1985. Competitive Advantage : Creating and Sustaining Superior Performance. New York: Free Press. Original edition. ISBN 0029250900.

Quail, B., Hill, G.A., and Jha, K.N. 1987. Correlations of Viscosity, Density and Gas Solubility for Saskatchewan Heavy Oils. Paper presented at the Technical 
Meeting / Petroleum Conference Of The South Saskatchewan Section, Regina. Petroleum Society of Canada PETSOC-SS-87-6. DOI: 10.2118/ss-87-6.

Rahimi, P., Fan, Z., Cooper, S. et al. 2009. Diluent Evaluation for Bitumen Pipelining. Paper presented at the 5th NCUT Upgrading and Refining Conference 2009, Edmonton, Alberta.

Shu, W.R. 1984. A Viscosity Correlation for Mixtures of Heavy Oil, Bitumen, and Petroleum Fractions. (06). DOI: 10.2118/11280-pa

Shu, W.R. and Venkatesan, V.N. 1984. Kintetics of Thermal Visbreaking of a Cold Lake Bitumen. Journal of Canadian Petroleum Technology 23 (2). DOI: 10.2118/8402-03

Suncor Pipeline Company. Local and Joint Tariff. http://psc.state.wy.us/htdocs/tariffs/wy_sep1/sep.pdf. 2012

Sutton, R.P. and Bergman, D.F. 2008. Application of the Bergman-Sutton Method for Determining Blend Viscosity. Paper presented at the SPE Eastern Regional/AAPG Eastern Section Joint Meeting, Pittsburgh, Pennsylvania, USA. 117711.

Ventech Engineers International Corp. Omimex Resources, Inc. Initial Visbreaker Unit Process Evaluation: Colombian Heavy Oil Production Field. 2005.

World Energy Council. 2010. Natural Bitumen and Extra-Heavy Oil. In 2010 Survey of Energy Resources:119-143. London.

Wiehe, I.A. 1993. A Phase-Separation Kinetic Model for Coke Formation. Industrial \& Engineering Chemistry Research 32 (11): 2447-2454. 
Wiehe, I.A. 2011. Process Chemistry of Petroleum Macromolecules. Ed Speight, J.G. Chemical Industries - a Series of Books and Textbooks. Boca Raton, FL: CRC Press. Original edition. ISBN 978-1-57444-787-3.

Wolf, C.O.H. and Tordo, S. 2009. The Petroleum Sector Value Chain. Washington, DC: World Bank.

Yang, Z. 2011. Viscosity Evaluation of Heavy Oils from Nmr Well Logging. Doctor of Philosophy, Rice University. 


\section{APPENDIX A}

The following tables provide oil and solvent data that make up part of the Excel code. Users are able to access this data at their convenience by entering the appropriate code.

Table 16 details the fluid properties of the oils while Table 17 details the fluid properties of the solvents.

Table 16-DATABASE OF THE DENSITY AND VISCOSITY OF HEAVY OILS

\begin{tabular}{|c|c|c|c|c|c|c|}
\hline & \multicolumn{2}{|c|}{ Athabasca Bitumen } & \multicolumn{2}{|c|}{ Cold Lake Bitumen } & \multicolumn{2}{|c|}{ Lloydminster } \\
\hline $\mathrm{T}\left({ }^{0} \mathrm{C}\right)$ & $\mu(\mathbf{c P})$ & $\rho\left(\mathrm{g} / \mathrm{cm}^{3}\right)$ & $\mu(\mathbf{c P})$ & $\rho\left(\mathrm{g} / \mathrm{cm}^{3}\right)$ & $\mu(\mathrm{cP})$ & $\rho\left(\mathrm{g} / \mathrm{cm}^{3}\right)$ \\
\hline 0 & 10000000 & 1.03 & 323985 & 1.00 & 48257 & 0.99 \\
\hline 5 & 4604735 & 1.02 & 188519 & 1.00 & 31298 & 0.99 \\
\hline 10 & 2120358 & 1.02 & 109694 & 1.00 & 20298 & 0.99 \\
\hline 15 & 976369 & 1.02 & 63828 & 0.99 & 13165 & 0.98 \\
\hline 20 & 449592 & 1.01 & 37140 & 0.99 & 8538 & 0.98 \\
\hline 25 & 207025 & 1.01 & 21611 & 0.98 & 5537 & 0.98 \\
\hline 30 & 95330 & 1.01 & 12575 & 0.98 & 3591 & 0.98 \\
\hline 40 & 20213 & 1.00 & 4258 & 0.97 & 1511 & 0.98 \\
\hline 50 & 4286 & 0.99 & 1442 & 0.97 & 635 & 0.98 \\
\hline
\end{tabular}


Table 17-DATABASE OF THE DENSITY AND VISCOSITY OF SOLVENTS

\begin{tabular}{|c|c|c|c|c|c|c|c|c|}
\hline & \multicolumn{2}{|c|}{ Naphtha } & \multicolumn{2}{c|}{ SCO } & \multicolumn{2}{c|}{ Gasoline } & \multicolumn{2}{c|}{ Toluene } \\
\hline $\left.\mathbf{T} \mathbf{(}^{\mathbf{0}} \mathbf{C}\right)$ & $\boldsymbol{\mu}(\mathbf{c P})$ & $\mathbf{( g / \mathbf { c m } ^ { \mathbf { 3 } } )}$ & $\boldsymbol{\mu} \mathbf{( c P )}$ & $\mathbf{( g / \mathbf { c m } ^ { 3 } )}$ & $\boldsymbol{\mu}(\mathbf{c P})$ & $\left(\mathbf{g} / \mathbf{c m}^{\mathbf{3}}\right)$ & $\boldsymbol{\mu} \mathbf{( c P )}$ & $\mathbf{( g / \mathbf { c m } ^ { \mathbf { 3 } } )}$ \\
\hline 0 & 1.58 & 0.830 & 9.12 & 0.872 & 0.508 & 0.746 & 14.426 & 0.885 \\
5 & 1.43 & 0.825 & 7.54 & 0.869 & 0.483 & 0.839 & 11.519 & 0.880 \\
10 & 1.30 & 0.820 & 6.32 & 0.865 & 0.459 & 0.835 & 9.198 & 0.876 \\
15 & 1.19 & 0.815 & 5.37 & 0.861 & 0.437 & 0.831 & 7.345 & 0.871 \\
20 & 1.097 & 0.810 & 4.61 & 0.858 & 0.416 & 0.827 & 5.865 & 0.866 \\
25 & 1.01 & 0.805 & 4.00 & 0.854 & 0.395 & 0.824 & 4.683 & 0.862 \\
30 & 0.94 & 0.800 & 3.50 & 0.851 & 0.376 & 0.820 & 3.740 & 0.857 \\
40 & 0.82 & 0.790 & 2.75 & 0.844 & 0.340 & 0.812 & 2.385 & 0.848 \\
50 & 0.72 & 0.780 & 2.22 & 0.837 & 0.308 & 0.805 & 1.520 & 0.838 \\
\hline
\end{tabular}

